\title{
Stealth monoolein-based nanocarriers for delivery of siRNA to cancer cells
}

\author{
Ana C.N. Oliveira ${ }^{\mathrm{a}, \mathrm{b}}$, Koen Raemdonck ${ }^{\mathrm{c}}$, Thomas Martens ${ }^{\mathrm{c}, \mathrm{d}}$, Koen Rombouts ${ }^{\mathrm{c}}$, Rosana Simón-Vázquez ${ }^{\mathrm{e}}$, \\ Cláudia Botelho ${ }^{\mathrm{f}}$, Ivo Lopes ${ }^{\mathrm{a}, \mathrm{b}}$, Marlene Lúcio ${ }^{\mathrm{b}}$, África González-Fernández ${ }^{\mathrm{e}}$, \\ M. Elisabete C.D. Real Oliveira ${ }^{\mathrm{b}}$, Andreia C. Gomes ${ }^{\mathrm{a}, *}$, Kevin Braeckmans ${ }^{\mathrm{c}, \mathrm{d}}$ \\ ${ }^{a}$ CBMA (Centre of Molecular and Environmental Biology), Department of Biology, University of Minho, Campus of Gualtar, 4710-057 Braga, Portugal \\ ${ }^{\mathrm{b}}$ Centre of Physics, Department of Physics, University of Minho, Campus of Gualtar, 4710-057 Braga, Portugal \\ ${ }^{\mathrm{c}}$ Laboratory of General Biochemistry and Physical Pharmacy, Faculty of Pharmacy, Ghent University, Harelbekestraat 72, 9000 Ghent, Belgium \\ ${ }^{\mathrm{d}}$ Center for Nano- and Biophotonics, Ghent University, Harelbekestraat 72, 9000 Ghent, Belgium

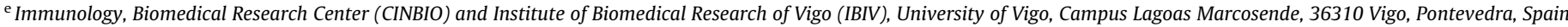 \\ ${ }^{\mathrm{f}}$ Centre of Biological Engineering (CEB), University of Minho, Campus of Gualtar, 4710-057 Braga, Portugal
}

\section{A R T I C L E I N F O}

\section{Article history:}

Received 15 January 2015

Received in revised form 13 July 2015

Accepted 23 July 2015

Available online 29 July 2015

\section{Keywords:}

FFS

fSPT

Monoolein

PEG

siRNA delivery

\begin{abstract}
A B S T R A C T
While the delivery of small interfering RNAs (siRNAs) is an attractive strategy to treat several clinical conditions, siRNA-nanocarriers' stability after intravenous administration is still a major obstacle for the development of RNA-interference based therapies. But, although the need for stability is well recognized, the notion that strong stabilization can decrease nanocarriers' efficiency is sometimes neglected. In this work we evaluated two stealth functionalization strategies to stabilize the previously validated dioctadecyldimethylammonium bromide (DODAB):monoolein (MO) siRNA-lipoplexes. The nanocarriers were pre- and post-pegylated, forming vectors with different stabilities in biological fluids. The stealth nanocarriers' behavior was tested under biological mimetic conditions, as the production of stable siRNA-lipoplexes is determinant to achieve efficient intravenous siRNA delivery to cancer cells. Upon incubation in human serum for $2 \mathrm{~h}$, by fluorescence Single Particle Tracking microscopy, PEG-coated lipoplexes were found to have better colloidal stability as they could maintain a relatively stable size. In addition, using fluorescence fluctuation spectroscopy, post-pegylation also proved to avoid siRNA dissociation from the nanocarriers in human serum. Concomitantly it was found that PEG-coated lipoplexes improved cellular uptake and transfection efficiency in H1299 cells, and had the ability to silence BCR-ABL, affecting the survival of K562 cells.

Based on an efficient cellular internalization, good silencing effect, good siRNA retention and good colloidal stability in human serum, DODAB:MO (2:1) siRNA-lipoplexes coated with PEG-Cer are considered promising nanocarriers for further in vivo validation.
\end{abstract}

\section{Statement of Significance}

This work describes two stealth functionalization strategies for the stabilization of the previously validated dioctadecyldimethylammonium bromide (DODAB):monoolein (MO) siRNA-lipoplexes. These nanocarriers are capable of efficiently incorporating and delivering siRNA molecules to cells in order to silence genes whose expression is implicated in a pathological condition. The main objective was to functionalize these nanocarriers with a coating conferring protection to siRNA in blood without compromising its efficient delivery to cancer cells, validating the potential of DODAB:MO (2:1) siRNA-lipoplexes as therapeutic vectors. We show that the stealth strategy is determinant to achieve a stable and efficient nanocarrier, and that DODAB:MO mixtures have a very promising potential for systemic siRNA delivery to leukemic cells. (C) 2015 Acta Materialia Inc. Published by Elsevier Ltd. All rights reserved.

\footnotetext{
Abbreviations: CLSM, confocal laser scanning microscopy; CML, chronic myeloid leukemia; DLS, dynamic light scattering; DODAB, dioctadecyldimethylammonium

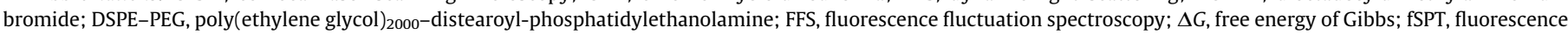

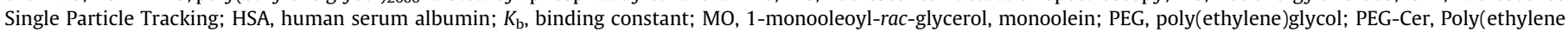
glycol $)_{2000} \mathrm{C}(8)$ ceramide; PEI, polyethylenimine; $\zeta$-potential, zeta potential.

* Corresponding author.

E-mail address: agomes@bio.uminho.pt (A.C. Gomes).
} 


\section{Introduction}

RNA interference (RNAi) is a natural mechanism by which short interfering RNAs (siRNAs) specifically inhibit protein synthesis [1]. The remarkable potential of this silencing mechanism has made siRNA therapy an important area in the biomedical field over the past years [2-7]. The scientific focus has not only been devoted to designing efficient siRNA molecules [8] but also to develop methods to deliver siRNAs to their site of action [9]. The development of nanocarriers has been the strategy of choice to provide protection, improve internalization by target cells and to optimize the intracellular trafficking of therapeutic siRNA molecules [9-12].

The design of nanocarriers for siRNA delivery must take into account properties such as small and uniform size distribution to allow internalization by endocytosis, and the ability to protect the encapsulated siRNA from enzymatic degradation. Biocompatibility and stability are additional requirements $[2,9,13,14]$. Systemic administration poses additional challenges to the nanocarriers, as interaction with serum proteins might induce premature release of siRNA and prompt aggregation [15-19]. Extended circulation times of stabilized delivery systems in the bloodstream has been mainly achieved by coating their surface with poly(ethylene glycol) (PEG). PEG is a highly soluble neutral polymer that forms a protective hydrophilic layer at the nanocarriers surface, providing a "steric stabilization" effect that changes the surface properties, reduces opsonization by blood proteins, and decreases uptake by phagocytic cell populations [20,21]. Steric stabilization can be achieved by other polymers besides PEG [22], but pegylation is still the most popular strategy to increase the circulation time of nanocarriers. Yet, steric stabilization provided by PEG was found to be undesirable during certain phases of the drug/nucleic acid delivery process. Pegylated nanocarriers might not satisfactorily protect nucleic acids against enzymatic degradation, and PEG can prevent nanocarriers cellular uptake or hinder siRNA endosomal escape [16,23-26]. To overcome these issues, exchangeable PEG-derivatives such as PEG-ceramides (PEG-Cer) have been proposed as a semi-stable coating, to provide good initial protection and stability in blood, while maintaining good cellular uptake and transfection [27]. Dissociation of the PEG-Cer chains from the siRNA nanocarrier will improve interaction with the cell membrane, cellular internalization and escape from endosomal compartments. However, it is not only the type of PEG that influences the transfection efficiency outcome, but also the pegylation method. Peeters et al. [23] prepared stealth nanocarriers by pre- and post-pegylation with PEG-Cer. The authors found that, even though the same type of PEG was used in both strategies, pre-pegylation of lipoplexes inhibited transfection efficiency due to slower internalization and entrapment inside endosomes, while post-pegylation improved transfection efficiency. Moreover, these and other authors have also shown that post-pegylation with DSPE-PEG leads to very low transfection efficiencies [23,25].

Recent work from our group has shown that liposomes prepared with dioctadecyldimethylammonium bromide (DODAB) and monoolein (MO) (DODAB:MO) are promising carriers for pDNA delivery [28-31]. The presence of MO on the formulation was found to be advantageous due to an increased fluidification of the nanocarrier membranes and stabilization of the liposomal structures [29,32,33]. DODAB:MO liposomes were also found to be suitable for siRNA delivery, as they efficiently encapsulated siRNA, were extensively taken up by the cells and were able to silence GFP expression without inducing cytotoxicity [34]. With this work we aimed to optimize the previously developed DODAB:MO (2:1) formulation for siRNA systemic delivery, by improving the nanocarriers' performance in physiological conditions. Taking previous reports into account [23,25], we have compared pre- and post-pegylation strategies in terms of stability in serum and capability to transfect cells. For pre-pegylation, DSPEPEG was added to the liposomes before complexation with siRNA. For post-pegylation, PEG-Cer was inserted into the already formed siRNA lipoplexes.

Advanced fluorescence microscopy techniques such as fluorescence Single Particle Tracking (fSPT) and fluorescence fluctuation spectroscopy (FFS) were used to characterize the stability of the nanocarriers and protection of siRNA in human serum $[15,16,18]$. Fluorescence spectroscopy was additionally used to assess if the presence of PEG influences the binding of human serum proteins to the liposomes. Gene silencing efficiency and cellular internalization were also evaluated and correlated with the nanocarriers' properties. The therapeutic potential of the siRNA-lipoplexes was further determined in a leukemia cell line model.

\section{Materials and methods}

\subsection{Materials}

Dioctadecyldimethylammonium bromide (DODAB), 1-monooleoyl-rac-glycerol (MO), dextran sulfate sodium salt, bovine serum albumin (BSA), and human serum albumin (HSA) were purchased from Sigma-Aldrich (Bornem, Belgium). Poly(ethylene glycol $)_{2000}$-distearoyl-phosphatidylethanolamine (DSPE-PEG) and poly(ethylene glycol) ${ }_{2000} \mathrm{C}(8)$ ceramide (PEG-Cer) were supplied by Avanti Polar Lipids (Alabaster, AL, USA). RPMI- $1640^{\circledR}$ and Opti-MEM ${ }^{\circledR}$ cell culture mediums, L-Glutamine, Fetal Bovine Serum (FBS), Trypsin-EDTA solution, PenicillinStreptomycin $(5000 \mathrm{IU} / \mathrm{ml}$ penicillin and $5000 \mu \mathrm{g} / \mathrm{ml}$ streptomycin), Geneticin ${ }^{\circledR}$ and phosphate-buffered saline (PBS) were ordered from Gibco (UK). Hoechst $n^{\circ}$ 33342, Lipofectamine RNAiMAx $^{\circledR}$ and 1,1'-Dioctadecyl-3,3,3',3'-Tetramethylindodicarbo cyanine Perchlorate oil ( $\operatorname{DilC}_{18}(5)$ oil $)\left(\lambda_{\mathrm{exc}}=644 \mathrm{~nm} ; \lambda_{\mathrm{em}}=665 \mathrm{~nm}\right)$ were purchased from Invitrogen (Merelbeke, Belgium). LysoSensor Green ${ }^{\circledR}$ was ordered from Molecular Probes (Merelbeke, Belgium). SV Total RNA Isolation System and CellTiter $96^{\circledR}$ AQueous One Solution Cell Proliferation Assay were obtained from Promega (Madison, USA). MTT assay was ordered from Roche (Germany). iScript $^{\mathrm{TM}}$ Reverse Transcription Supermix for RT-qPCR and the iTaq $^{\mathrm{TM}}$ Universal $\mathrm{SYBR}^{\circledR}$ Green Supermix were purchased from Bio-Rad (USA). siRNA targeting the enhanced green fluorescent protein (siEGFP) and a universal negative control duplex (siCTRL) were obtained from Eurogentec (Seraing, Belgium). Confocal microscopy and uptake experiments were performed with a $\mathrm{Cy}^{\circledR} 5$-labeled siRNA duplex (Eurogentec, Seraing, Belgium). siRNA targeting the BCR-ABL protein (siBCR-ABL) and a scrambled sequence (siSCRAMB) were purchased from IDT (Iowa, USA). The nucleic acids sequences are shown in Table 1 . siRNAs were prepared at $20 \mu \mathrm{M}$ in DEPC-treated water and stored at $-20^{\circ} \mathrm{C}$ until used.

\subsection{Preparation of liposomes and siRNA-lipoplexes}

In order to coat the nanocarriers, cationic liposomes composed by DODAB:MO (molar ratio 2:1 (mol:mol)) and DSPE-PEG were prepared by a pre-pegylation methodology. Briefly, defined

Table 1

Nucleic acid sequences used in the silencing experiments. Sense strands are represented. Lower case letters represent 2'-deoxyribonucleotides.

\begin{tabular}{ll} 
siEGFP & 5'-CAAGCUGACCCUGAAGUUCtt-3' \\
siCTRL & 5'-UGCGCUACGAUCGACGAUGtt-3' \\
siBCR-ABL & 5'-AAGGGCUUUUGAACUCUGCtt-3' \\
siSCRAMB & 5'-GUCUCAAGUUUUCGGGAAGtt-3' \\
\hline
\end{tabular}




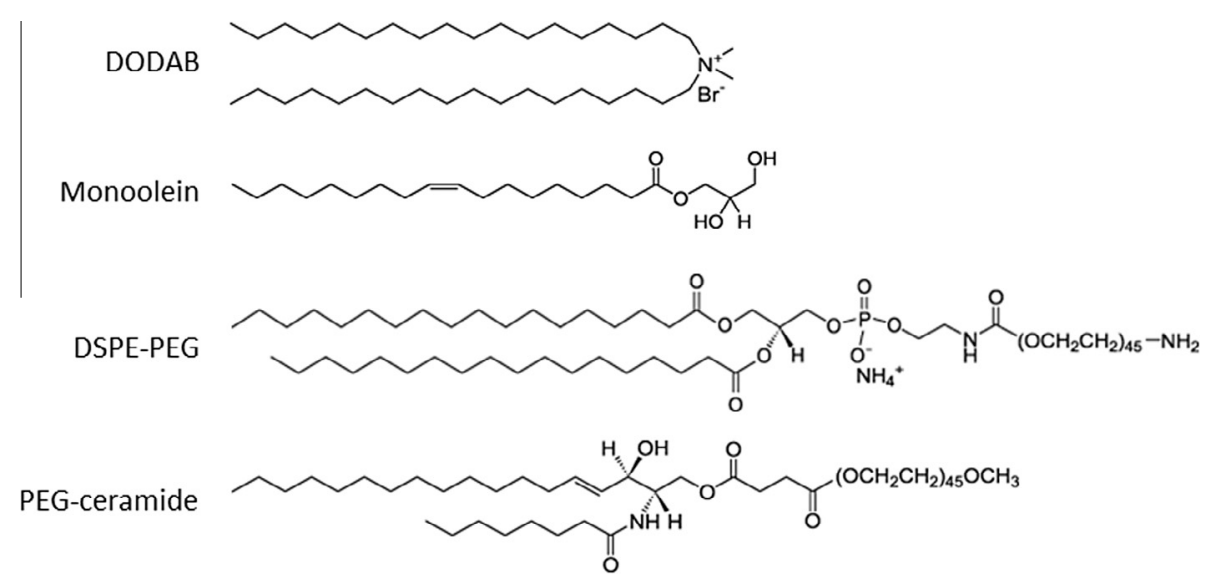

Fig. 1. Structure of the lipids used during this work.

volumes of DODAB and MO (20 mM stock solutions in ethanol) and DSPE-PEG ( $1 \mathrm{mg} \mathrm{mL}^{-1}$ stock solution in chloroform) were placed in a round-bottomed flask and the solvents evaporated under vacuum at $40^{\circ} \mathrm{C}$. The lipid film was hydrated $\left(>50^{\circ} \mathrm{C}\right)$ with $1 \mathrm{~mL}$ HEPES buffer ( $25 \mathrm{mM} \mathrm{pH} \mathrm{7.4)} \mathrm{to} \mathrm{a} \mathrm{final} \mathrm{total} \mathrm{lipid} \mathrm{concentration} \mathrm{of}$ $5 \mathrm{mM}$, forming PEG 0\%/DODAB:MO, PEG 5\%/DODAB:MO, PEG 10\%/DODAB:MO, and PEG 15\%/DODAB:MO liposomes, herein referred as Peg0, Peg5, Peg10, and Peg15 liposomes. Finally, liposomes were extruded at room temperature (RT) 11 times through a $100 \mathrm{~nm}$ pore sized polycarbonate membrane (Whatman, USA) using the Avanti Polar Lipids Mini-extruder. siRNA-lipoplexes incorporating DSPE-PEG were prepared by incubation of siRNA (diluted

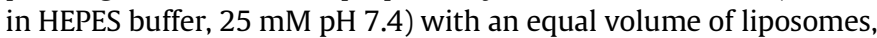
at the defined lipid concentration to form the desired charge ratio $(+/-)$. siRNA-lipoplexes were incubated for $20 \mathrm{~min}$ at RT before use.

Liposomes and siRNA-lipoplexes composed by DODAB:MO (2:1) were also prepared with PEG-Cer by post-pegylation. Briefly, liposomes DODAB:MO (2:1) were formed, and DODAB:MO $(2: 1)(+/-) 15$ lipoplexes were prepared by the incubation of siRNA with liposomes, as described. Subsequently, defined volumes of PEG-Cer ( $1 \mathrm{mg} \mathrm{mL}^{-1}$ stock solution in chloroform) were added to the liposomes or siRNA-lipoplexes and incubated for $1 \mathrm{~h}$ at $60^{\circ} \mathrm{C}$, for the integration of the PEG-Cer chains onto the liposomal membranes. PEG-Cer 0\%/DODAB:MO, PEG-Cer 5\%/DODAB:MO, PEG-Cer 10\%/DODAB:MO and PEG-Cer 15\%/DODAB:MO liposomes, or siRNA-lipoplexes at charge ratio (+/-) 15 were obtained, which will be referred as PegCer0, PegCer5, PegCer10, and PegCer15 liposomes or siRNA-lipoplexes, for simplification.
(Malvern, UK), equipped with Dispersion Technology Software (DTS). All results were based on intensity distributions.

\subsection{Scanning transmission electron microscopy (STEM)}

Peg0, Peg10, PegCer0 and PegCer10 liposomes were analyzed by Field Emission Gun Scanning Electron Microscopy (FEG-SEM). Liposomes were installed in Cu-C grids (S160-4 AGAR) by immersion in the solution, and morphological analyses were realized in an Ultra-high resolution FEG-SEM, NOVA 200 Nano SEM, FEI Company. An acceleration voltage of $17.5 \mathrm{kV}$ and a Scanning Transmission Electron Detector (STEM) were used.

\subsection{Fluorescence fluctuation spectroscopy (FFS)}

The amount of siRNA released from the siRNA-lipoplexes, when dispersed in human serum (HS), was determined by fluorescence fluctuation spectroscopy (FFS) as previously described $[15,16,19,35]$. In FFS, fluorescence intensity fluctuations are monitored in the focal volume $(\sim 1 \mathrm{fL})$ of a confocal microscope as a function of time. Free fluorescently labeled siRNA molecules give rise to a certain 'baseline' intensity, while intense fluorescence peaks are observed when siRNA-lipoplexes (containing many molecules of fluorescent siRNAs) diffuse in and out of the focal volume (Supplementary information, Fig. S1). The percentage of SiRNA that is released upon incubation of the lipoplexes in serum can be quantified according to Eq. (1) [16]:

$\%$ free siRNA $=\frac{(\text { free siRNA BL }- \text { medium } B L)-(\text { free siRNA BL }- \text { complexed siRNA })}{(\text { free siRNA BL }- \text { medium } B L)} \times 100$

The chemical structures of the lipids used during this work are shown in Fig. 1.

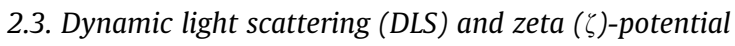

Dynamic light scattering (DLS) was used to determine the mean size, polydispersity index (PDI) and surface charge of liposomes and siRNA-lipoplexes. Liposomes were measured in HEPES buffer,

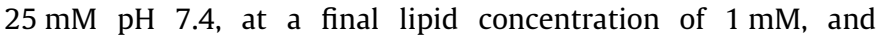
siRNA-lipoplexes were prepared with $200 \mathrm{nM}$ siCTRL. Measurements were made at $25^{\circ} \mathrm{C}$ in a Zetasizer Nano ZS where free siRNA BL is the siRNA baseline fluorescence signal if all siRNA is free (positive control), medium $B L$ is the baseline signal recorded from samples dispersed in the medium of interest, and complexed siRNA is the fluorescence signal associated with the initial stock solution of siRNA-lipoplexes (negative control).

FFS measurements were performed to determine the extent of siRNA release from siRNA-lipoplexes when dispersed in $\mathrm{HS}$. siRNA-lipoplexes were prepared with $50 \mathrm{nM}$ Cy $5{ }^{\circledR}$-siRNA in HEPES buffer, and incubated in 50\% HS (lipoplexes:HS 50:50 v:v) at $37^{\circ} \mathrm{C}$ to determine siRNA release over time. siRNA baseline signals were obtained by measuring the fluorescence of free Cy $5^{\circledR}$-siRNA in $50 \%$ HS or HEPES buffer, and the background 
fluorescence was recorded from samples containing 50\% HS or HEPES buffer alone. Measurements were made at defined time points on a Nikon C1 confocal laser scanning microscope (Nikon Belux, Brussels, Belgium) equipped with a Plan Apo VC $60 \times 1.2$ NA water immersion objective lens with collar rim correction. The laser was focused at about $100 \mu \mathrm{m}$ above the bottom of a glass-bottom 96-well plate (Greiner Bio-one, Frickenhausen, Germany), and measurements of $30 \mathrm{~s}$ were performed.

\subsection{Fluorescence Single Particle Tracking (fSPT)}

siRNA-lipoplexes aggregation in full HS was followed by fluorescence Single Particle Tracking (fSPT) as a function of time [18]. Briefly, fluorescent DiIC18(5) oil-labeled DODAB:MO (2:1) (1\% $\mathrm{mol}: \mathrm{mol})$ liposomes were used to form siRNA-lipoplexes at charge ratio (+/-) 15 (250 nM siCTRL), and PEG-Cer was incorporated as described. Different pegylation degrees (0\%, 5\%, 10\% and 15\%) were tested. siRNA-lipoplexes were subsequently diluted in HEPES buffer $(1: 20 \mathrm{v}: \mathrm{v})$ and incubated in full HS at $37^{\circ} \mathrm{C}$. For each time point, $7 \mu \mathrm{L}$ of the sample was placed in a microscope slide and covered with a cover glass, using a double-sided adhesive sticker of $120 \mu \mathrm{m}$ thickness (Secure-Seal Spacer, Molecular Probes, Leiden, The Netherlands) to create a closed chamber. The microscope was focused between 5 and $10 \mu \mathrm{m}$ from the cover glass and 20 movies of $10 \mathrm{~s}$ each were recorded at different locations within the sample. A custom-built laser widefield epi-fluorescence microscope set-up, with a TE2000-E inverted microscope equipped with a Nikon Plan Apo VC $100 \times 1.4$ NA oil immersion objective lens (Nikon Belux, Brussels, Belgium) was used for the fSPT measurements. siRNA-lipoplexes were excited with a $636 \mathrm{~nm}$ diode laser (IQ1C, Power Technology, Little Rock, AR), and the red emission channel was defined in the spectral range between 655 and $745 \mathrm{~nm}$. Images were registered with an EMCCD camera (Cascade II:512, Roper Scientific, Tucson, AZ) synchronized with an acousto-optical tunable filter (AOTF), to illuminate the sample only during the camera exposure time, minimizing this way potential photobleaching. The image acquisition was done with the NIS Elements imaging software (Nikon Belux, Brussels, Belgium) at a frame speed of 33 frames per second and exposure times of $10 \mathrm{~ms}$. The analysis of fSPT movies was performed off-line, as previously reported [18]. Briefly, trajectories were calculated using the nearest neighbor algorithm, and the mean diffusion coefficient was obtained for each trajectory using an algorithm based on the mean square displacement analysis. Using the Stokes-Einstein equation, the distribution of the diffusion coefficients was transformed in a size distribution, and the actual size distribution was finally obtained using a Maximum Entropy deconvolution process.

\subsection{Fluorescence spectroscopy (FS)}

Fluorescence spectroscopy (FS) was used to evaluate the effect of PEG-Cer on the binding of human serum albumin (HSA) to liposomes, and the binding constant $\left(K_{\mathrm{b}}\right)$ and the free energy of Gibbs $(\Delta G)$ were determined for three temperatures, according to Copeland et al. [36] (Supplementary information, Fig. S2). Briefly, HSA protein solutions (18 $\mu \mathrm{M}$ in HEPES buffer, $\mathrm{pH} 7.425 \mathrm{mM}$ ) were incubated with increasing concentrations of liposomes, and the fluorescence emission spectra $(300-450 \mathrm{~nm})$ were recorded in a Horiba Jobin Yvon Spex Fluorolog-3 spectrofluorimeter, using a $\lambda_{\text {exc }}=291 \mathrm{~nm}$, with spectral bandwidths of $1 \mathrm{~nm}$, at 25, 30 and $37^{\circ} \mathrm{C}$.

FS was also used to evaluate the interaction of siRNA-lipoplexes with the serum proteins fibrinogen, globulins and HSA, by tryptophan fluorescence emission, as described elsewhere [37]. Briefly, protein solutions $\left(1000,350\right.$ and $800 \mu \mathrm{g} \mathrm{mL}^{-1}$ of HSA, fibrinogen and globulins, respectively), prepared in PBS, were incubated with siRNA-lipoplexes (50 $\mathrm{nM}$ siCTRL) at a ratio 98:2 (v:v). Fluorescence emission spectra $(300-450 \mathrm{~nm})$ were recorded in a Wallac Enviosin plate reader (Perkin-Elmer) using a $\lambda_{\text {exc }}=270 \mathrm{~nm}$, with spectral bandwidths of $2 \mathrm{~nm}$. For every measurement, two spectra were recorded and the average calculated using the FluorEssence TM software. The measured signal was normalized, so that the spectral shift could be better visualized.

\subsection{Cell lines and culture conditions}

Several cell lines: K562, H1299 wild type (H1299 wt) and H1299 stably expressing enhanced green fluorescent protein (H1299 eGFP) were grown in RPMI $1640^{\circledR}$ cell culture medium supplemented with $1 \%$ L-glutamine, $10 \%$ FBS and $2 \%$ penicillin-strepto mycin. Cells were maintained in a humidified incubator, at $37^{\circ} \mathrm{C}$ and $5 \% \mathrm{CO}_{2}$. $\mathrm{H} 1299$ cells were passed every 3 days using $0.05 \%$ Trypsin-EDTA solution, and H1299 eGFP cells were additionally treated with $1 \mathrm{mg} \mathrm{mL}^{-1}$ Geneticin ${ }^{\circledR}$ once per month for selection. K562 cells were passed every $3-4$ days at a cell density $0.5 \times 10^{5}$ cells $\mathrm{mL}^{-1}$ to maintain sub-confluency.

\subsection{Flow cytometry}

Flow cytometry was used for the evaluation of EGFP gene silencing on H1299 eGFP cells and for the quantification of siRNA-lipoplexes cellular uptake. For the EGFP gene silencing evaluation, H1299 eGFP cells were seeded on 24-multiwell plates at a density of $35 \times 10^{5}$ cells per well and grown overnight. Complete cell culture medium was replaced by Opti-MEM ${ }^{\circledR}$ and $100 \mu \mathrm{L}$ of siRNA-lipoplex solutions (with $50 \mathrm{nM}$ siCTRL or $50 \mathrm{nM}$ siEGFP) was added. After $4 \mathrm{~h}$ incubation, Opti-MEM ${ }^{\circledR}$ was replaced by fresh cell culture medium, and cells were further incubated for $44 \mathrm{~h}$ at $37{ }^{\circ} \mathrm{C}$ and $5 \% \mathrm{CO}_{2}$. Finally, cells were washed with PBS, trypsinized ( $0.25 \%$ trypsin-EDTA) and diluted with $1 \mathrm{~mL}$ complete cell culture medium. After centrifugation ( $1400 \mathrm{rpm}, 7 \mathrm{~min}$ ), the cell pellet was resuspended in $300 \mu \mathrm{L}$ flow buffer ( $1 \% \mathrm{BSA}$ and $0.1 \%$ sodium azide in PBS) and kept on ice until EGFP expression was quantified using a Beckman Coulter Cytomics FC500 flow cytometer equipped with an argon laser (excitation at $488 \mathrm{~nm}$ ). The silencing experiments were performed in triplicate and $20 \times 10^{3}$ cells were considered for each sample. The percentage of downregulation was expressed according to Eq. (2):

$\%$ Downregulation $=(1-\operatorname{siEGFP} /$ siCTRL $) \times 100$

where SiEGFP and siCTRL are the mean EGFP fluorescence intensity of cells treated with siRNA-lipoplexes prepared with siEGFP and siCTRL, respectively.

For the siRNA-lipoplexes uptake experiments, H1299 eGFP cells were seeded into 24 -multiwell plates at a density of $35 \times 10^{5}$ cells per well and grown overnight. After the complete cell culture medium was replaced by Opti-MEM ${ }^{\circledR}, 100 \mu \mathrm{L}$ siRNA-lipoplexes prepared with $50 \mathrm{nM}$ siCTRL $\left(2 \% \mathrm{Cy} 5^{\circledR}\right.$-labeled siRNA) was added to each well. After $4 \mathrm{~h}$ incubation at $37^{\circ} \mathrm{C}$, cells were washed with $0.1 \mathrm{mg} \mathrm{mL}^{-1}$ dextran sulfate solution for $5 \mathrm{~min}$ to remove non-internalized siRNA-lipoplexes and further prepared for analysis as described for the gene silencing assay (excitation of $\mathrm{Cy} 5^{\circledR}$ at $633 \mathrm{~nm}$ ). Experiments were performed in triplicate and $10 \times 10^{3}$ cells were considered for each sample.

\subsection{Confocal laser scanning microscopy (CLSM)}

H1299 cells were seeded on glass bottomed $35 \mathrm{~mm}$ cell culture dishes (Greiner, Germany) at a cell density of $1.25 \times 10^{5}$ cells per dish and grown overnight. Complete cell culture medium was 
replaced by Opti-MEM ${ }^{\circledR}$ and cells were incubated with $100 \mu \mathrm{L}$ siRNA-lipoplexes (50 nM siRNA, 50\% Cy $5{ }^{\circledR}$-labeled siRNA and 50\% siCTRL) for $4 \mathrm{~h}$ at $37^{\circ} \mathrm{C}$. After the incubation period, a washing step with $0.1 \mathrm{mg} \mathrm{mL}^{-1}$ dextran sulfate solution was performed to remove the non-internalized siRNA-lipoplexes. PBS was then used to remove dextran sulfate and complete cell culture medium was added to the cells. Cells were observed on a Nikon C1 confocal laser scanning microscope (Nikon Belux, Brussels, Belgium) equipped with a Plan Apo VC $60 \times 1.2$ NA water immersion objective lens. Cell nucleus was stained with Hoechst $n^{\circ} 33342(1 \mu \mathrm{M}, 15 \mathrm{~min})$ and endo-lysosomal compartments with LysoSensor Green ${ }^{\circledR}$ $(1 \mu \mathrm{M}, 1 \mathrm{~h})$.

\subsection{Quantitative real time PCR ( $q P C R$ )}

Quantitative real time PCR ( $\mathrm{qPCR}$ ) was used to evaluate knockdown of the $B C R-A B L$ gene in the K562 cell line. K562 cells were seeded on 12-multiwell plates, at a cell density of $1 \times 10^{5}$ cells per well, in RPMI ${ }^{\circledR}$ cell culture medium without FBS, and $100 \mu \mathrm{L}$ of siRNA-lipoplex solutions, prepared with $100 \mathrm{nM}$ siSCRAMB or $100 \mathrm{nM}$ siBCR-ABL, were immediately added to each well. Lipofectamine RNAiMax ${ }^{\circledR}$ lipoplexes (100 nM siRNA) were used as a control, and prepared according to manufacturer's instructions. After $4 \mathrm{~h}$ incubation, RPMI ${ }^{\circledR}$ was replaced by complete cell culture medium, and cells were further incubated for $20 \mathrm{~h}$ at $37{ }^{\circ} \mathrm{C}$ and $5 \% \mathrm{CO}_{2}$. Total RNA from transfected cells was isolated and purified using the SV Total RNA Isolation System (Promega, Madison, USA) according to manufacturer's instructions. RNA quality and concentration were verified in the NanoDrop ND1000 Spectrophotometer (Thermo Scientific). Total RNA (275 ng) was converted into cDNA using the iScript ${ }^{\mathrm{TM}}$ Reverse Transcription Supermix for RT-qPCR (Bio-Rad, USA), according to instructions. The following protocol was used: 1 st step, $5 \mathrm{~min}$ at $25^{\circ} \mathrm{C}$; 2nd step, $60 \mathrm{~min}$ at $42{ }^{\circ} \mathrm{C}$; $3 \mathrm{rd}$ step, $5 \mathrm{~min}$ at $85^{\circ} \mathrm{C}$. cDNA was used for qPCR analysis using iTaq ${ }^{\mathrm{TM}}$ Universal SYBR ${ }^{\circledR}$ Green Supermix (Bio-Rad, USA) in the CFX96 ${ }^{\mathrm{TM}}$ Real-Time PCR System (Bio-Rad). Purified salt-free primers for target gene $B C R-A B L$ (forward primer $5^{\prime}$-TCC GCTGACCATCAATAAGGA- $3^{\prime}$ and reverse primer $5^{\prime}$-CACTCAGACCC TGAGGCTCAA- $3^{\prime}$ ) and for the reference gene GADPH (forward primer 5'-AGGTCGGTGTGAACGGATTTG-3' and reverse primer 5'-TG TAGACCATGTAGTTGAGGTCA-3') were generated. The qPCR reaction was performed in 96-well PCR plates (iCycler iQ, Bio-Rad) as follows: one cycle of $30 \mathrm{~s}$ at $95^{\circ} \mathrm{C}$, followed by 40 PCR cycles at $95^{\circ} \mathrm{C} \times 5 \mathrm{~s}$ and $61^{\circ} \mathrm{C} \times 30 \mathrm{~s}$. A melting curve was made immediately after the qPCR, to demonstrate the specificity of the amplification, consisting in 1 cycle of $95^{\circ} \mathrm{C} \times 60 \mathrm{~s}$ and $55^{\circ} \mathrm{C} \times 60 \mathrm{~s}$, followed by an increase in temperature from 55 to $95^{\circ} \mathrm{C}$, with $0.5^{\circ} \mathrm{C}$ increments in each step. No template controls were always evaluated for each target gene. Relative gene expression values were determined according to Pfaffl 2001 [38]. Quantification cycle (Cq) values were generated automatically by the Bio-Rad CFX Manager 2.0 Software, and the ratio of the target gene $B C R-A B L$ was expressed in comparison to the reference gene $G A D P H$, according to Eq. (3):

ratio $=\frac{E_{\text {target }}^{\Delta C q_{\text {target }}}}{E_{\text {ref }}^{\Delta C q_{\text {ref }}}}$,

where $E_{\text {target }}$ is the real-time PCR efficiency of the BCR-ABL transcript; $E_{\text {ref }}$ is the real-time PCR efficiency of the GADPH reference gene transcript; $\Delta C q_{\text {target }}=\mathrm{Cq}_{\text {control }}-\mathrm{Cq}_{\text {sample }}$ of the target gene transcript; and $\Delta C q_{\text {ref }}=\mathrm{Cq}_{\text {control }}-\mathrm{Cq}_{\text {sample }}$ of the reference gene transcript. Real-time PCR efficiencies were calculated according to $E=10^{(-1 / \text { slope })}$, and were found to be between $95 \%$ and $115 \%$, with $R^{2}>0.99$.

\subsection{Cell survival assays}

Cytotoxicity assays were performed to determine the percentage of H1299 eGFP viable cells after incubation with siRNA-lipoplexes, as well as to evaluate the effect of the $B C R-A B L$ downregulation on K562 cell survival. Briefly, H1299 eGFP cells were seeded into 24 -multiwell plates at a density of $35 \times 10^{5}$ cells per well and grown overnight. The complete cell culture medium was replaced by Opti-MEM ${ }^{\circledR}$ and $100 \mu \mathrm{L}$ of siRNA-lipoplex solutions ( $50 \mathrm{nM}$ siCONTROL) were added to each well. After a $4 \mathrm{~h}$ incubation period at $37{ }^{\circ} \mathrm{C}, 5 \% \mathrm{CO}_{2}$, the supernatant was removed and replaced by fresh cell culture medium. After $44 \mathrm{~h}$ cell viability was assessed with the MTT assay. K562 cells were seeded on 96-multiwell plates, at a cell density of $1 \times 10^{5}$ cells per well, in RPMI $^{\circledR}$ cell culture medium without FBS. DODAB:MO $(2: 1)$ nanocarriers were added to the cells as described above, with $100 \mathrm{nM}$ siSCRAMB, $100 \mathrm{nM}$ siBCR-ABL, or as empty liposomes. Lipofectamine RNAiMax ${ }^{\circledR}$ was used as control. After $72 \mathrm{~h}$ cell viability was assessed with the CellTiter $96^{\circledR}$ AQueous One Solution Cell Proliferation Assay according to manufacturer's instructions. Non-treated (NT) cells were set to $100 \%$ cell survival. The percentage of effective cell survival was determined by normalizing the cytotoxicity obtained after treatment with siBCR-ABL lipoplexes against the empty vectors' cytotoxicity.

\subsection{Statistical analysis}

Statistical analysis was performed with GraphPad Prism 5.0 Software. The one-way ANOVA test was used followed by a Dunnett's post-test. Results were expressed as mean \pm standard deviation (S.D.). Statistical significance is highlighted as follow: ${ }^{*} p \leqslant 0.05,{ }^{* *} p \leqslant 0.01,{ }^{* * *} p \leqslant 0.001$.

\section{Results}

3.1. Pegylation strategy does not significantly affect the nanocarriers physicochemical characteristics

DODAB:MO (2:1) liposomes were previously validated for pDNA and siRNA delivery, showing a good transfection activity without inducing significant cytotoxicity [28,30,34]. In this study
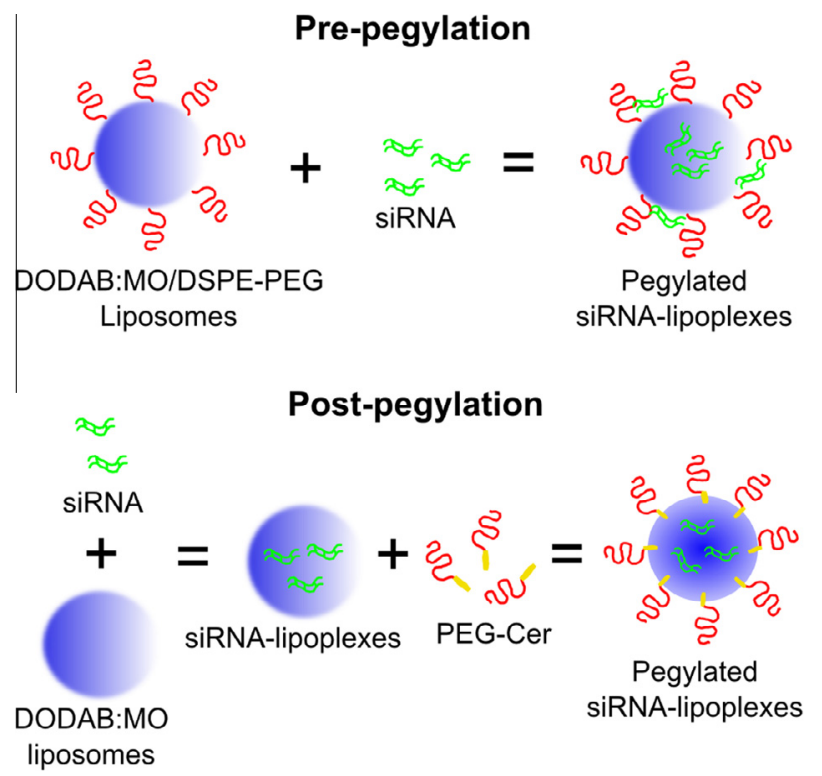

Fig. 2. Schematic representation of the two pegylation strategies studied. 
Table 2

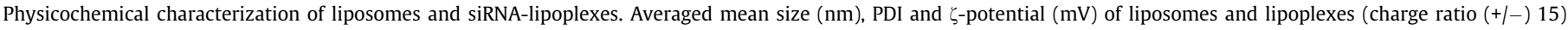

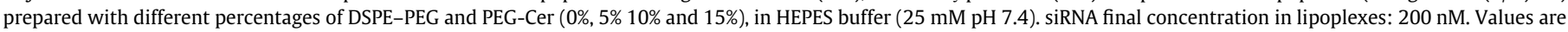
the average \pm S.D. of 3 measurements on the same sample.

\begin{tabular}{|c|c|c|c|c|c|c|c|}
\hline & \multirow[t]{2}{*}{$\%$ of PEG } & \multicolumn{3}{|l|}{ Liposomes } & \multicolumn{3}{|c|}{ siRNA-lipoplexes } \\
\hline & & Mean size & PDI & $\zeta$-Potential & Mean size & PDI & $\zeta$-Potential \\
\hline \multirow[t]{4}{*}{ DSPE-PEG (pre-pegylation) } & Peg0 & $116 \pm 1$ & $0.11 \pm 0.02$ & $49 \pm 1$ & $135 \pm 1$ & $0.13 \pm 0.01$ & $47 \pm 1$ \\
\hline & Peg5 & $124 \pm 1$ & $0.09 \pm 0.01$ & $19 \pm 1$ & $137 \pm 1$ & $0.11 \pm 0.03$ & $15 \pm 1$ \\
\hline & Peg10 & $124 \pm 2$ & $0.09 \pm 0.02$ & $17 \pm 2$ & $129 \pm 1$ & $0.10 \pm 0.01$ & $14 \pm 5$ \\
\hline & Peg15 & $111 \pm 0$ & $0.11 \pm 0.02$ & $10 \pm 0$ & $117 \pm 3$ & $0.18 \pm 0.02$ & $10 \pm 0$ \\
\hline \multirow{4}{*}{ PEG-Cer (post-pegylation) } & PegCer0 & $106 \pm 1$ & $0.12 \pm 0.01$ & $56 \pm 2$ & $137 \pm 1$ & $0.18 \pm 0.02$ & $55 \pm 2$ \\
\hline & PegCer5 & $118 \pm 1$ & $0.12 \pm 0.01$ & $32 \pm 1$ & $130 \pm 1$ & $0.20 \pm 0.01$ & $26 \pm 3$ \\
\hline & PegCer10 & $121 \pm 1$ & $0.12 \pm 0.02$ & $31 \pm 1$ & $127 \pm 2$ & $0.12 \pm 0.00$ & $27 \pm 0$ \\
\hline & PegCer15 & $124 \pm 2$ & $0.11 \pm 0.02$ & $20 \pm 2$ & $126 \pm 1$ & $0.13 \pm 0.01$ & $15 \pm 1$ \\
\hline
\end{tabular}

we have chosen two stealth functionalization strategies combining two pegylation methods (pre- or post-pegylation) to optimize siRNA encapsulation and protection in serum (Fig. 2). Our aim is to obtain a coating able to provide good encapsulation and protection to siRNA in blood but at the same time allowing an efficient siRNA delivery to cancer cells, validating the potential of DODAB:MO (2:1) siRNA-lipoplexes as therapeutic vectors.

The effect of the two stabilization approaches on the mean size and surface charge of DODAB:MO (2:1) liposomes and siRNA-lipoplexes is shown in Table 2 and Fig. 3. Before characterization, siRNA encapsulation was assessed by a gel retardation assay, and all liposomal formulations were found to entirely encapsulate the siRNA at charge ratio (+/-) 15 (Supplementary information, Fig. S3).

With both strategies, the surface charge of liposomes and siRNA-lipoplexes decreased with increasing percentage of grafted PEG, although a positive surface charge could still be measured for the higher percentage of PEG tested $(>+10 \mathrm{mV})$. The heating step required for the incorporation of PEG-Cer chains on the liposomal membranes slightly influenced the surface charge of liposomes: $\zeta$-potential of $+49 \mathrm{mV}$ for Peg0 liposomes (no heating), and $+56 \mathrm{mV}$ for PegCer0 liposomes (heating at $60^{\circ} \mathrm{C}$ for $1 \mathrm{~h}$ for the incorporation of the PEG-Cer chains). The same trend was observed for siRNA-lipoplexes. Table 2 shows that all formulations have a homogeneous size distribution (PDI <0.2). Furthermore, they present mean sizes bellow $140 \mathrm{~nm}$, and the size of the nanocarriers did not appreciably change by the pegylation process. Fig. 3 shows STEM micrographs of selected liposome dispersions, confirming that small and homogeneous populations are obtained. No significant aggregation was detected for all the samples.

\subsection{Pegylation strategy influences lipoplex stability in physiological conditions and interaction with human serum proteins}

Once nanocarriers are administered intravenously, as required for treatment of pathologies such as leukemia, they immediately come into contact with blood constituents, including cells such as erythrocytes, platelets and leukocytes, or plasma proteins. Such interactions can not only trigger cellular immune responses, but also alter the physicochemical characteristics of the nanocarriers, compromising their efficiency. The binding of serum proteins to nanocarriers is a main driving force for aggregation and premature release of the nanocarriers' payload, significantly decreasing its possibility of success. Therefore, the study of the interface between nanocarriers and serum constituents is essential for the development of any systemic drug or nucleic acid delivery system. We performed a detailed evaluation of the stability of DODAB:MO (2:1) siRNA-lipoplexes in human serum (HS) by quantifying siRNA dissociation from siRNA-lipoplexes by fluorescence fluctuation spectroscopy (FFS) and siRNA-lipoplexes aggregation by fluorescence Single Particle Tracking (fSPT) (Fig. 4).
siRNA dissociation measurements were made immediately after incubation of $\mathrm{Cy} 5^{\circledR}$-labeled siRNA-lipoplexes with HS $(0 \mathrm{~h})$, and after $1 \mathrm{~h}$ and $2 \mathrm{~h}$ incubation (Fig. 4A and B). Fig. 4A shows that, although free siRNA was detected in all samples prepared in HEPES buffer, pegylation with DSPE-PEG resulted in slightly higher values of uncomplexed siRNA. Actually, as the percentage of DSPE-PEG increased, more non-encapsulated siRNA could be detected (Fig. 4A), going from $\sim 10 \%$ to $18 \%$ detected free siRNA. The opposite was observed for PEG-Cer (Fig. 2B), with non-encapsulated siRNA going from $6 \%$ to $3 \%$ with the increase in PEG-Cer percentage. When siRNA-lipoplexes were incubated in HS, siRNA release was immediately observed, increasing gradually over time for all the samples (Fig. 4A and B). Nevertheless, pegylation with DSPEPEG resulted in higher siRNA release from the system when compared to pegylation with PEG-Cer. The presence of higher percentages of DSPE-PEG promoted siRNA dissociation: after $2 \mathrm{~h}$ incubation, 65\% siRNA was displaced from Peg0 lipoplexes, while $85 \%$ was released from Peg15 lipoplexes. The effect of the heating step required for the incorporation of PEG-Cer in the siRNA-lipoplexes influenced the stability of the nanocarriers, since less siRNA was released from PegCer0 lipoplexes when compared to Peg0 lipoplexes (no heating) for all the time points. siRNA dissociation from PEG-Cer siRNA-lipoplexes was always less than $50 \%$, even after $2 \mathrm{~h}$ incubation in HS (Fig. 4B).

Since PEG-Cer siRNA-lipoplexes provided the best protection of siRNA in serum (Fig. 4A versus B), further experiments were performed to test their colloidal stability, because this could be compromised by a fast dissociation of the PEG moieties from liposome bilayers. Aggregation of DODAB:MO (2:1) siRNA-lipoplexes in HS was determined by fSPT, and the siRNA-lipoplex size distributions, obtained according to Section 2.7 in materials and methods, are shown in Fig. 4C and D. A clear difference in size distribution between pegylated and non-pegylated siRNA-lipoplexes could be observed immediately after incubation of the nanocarriers with HS (Fig. 4C versus D, Control (tOh) - gray lines). Non-pegylated nanocarriers (Fig. 4C, gray line) show a much broader size distribution than pegylated ones (Fig. 4D, gray line), compatible with a more homogeneous population of smaller nanocarriers in the latter. After $2 \mathrm{~h}$ incubation in HS (Fig. 4C and D, dark lines), pegylated lipoplexes maintained better colloidal stability (mean sizes 140 to $150 \mathrm{~nm}$ ) than non-pegylated lipoplexes (mean size >200 nm), independently of the PEG-Cer percentage.

In order to determine if the presence of PEG-Cer on the liposome surface can reduce interaction with proteins, the binding of HSA to non-pegylated and pegylated liposomes was evaluated by fluorescence spectroscopy (FS) (Fig. 5A and B). Additionally, we evaluated if interaction with siRNA-lipoplexes might induce conformational changes to human serum proteins (Fig. 5C).

After the addition of DODAB:MO (2:1) PegCer0, PegCer5 and PegCer15 liposomes to the protein solutions, a decrease in the 

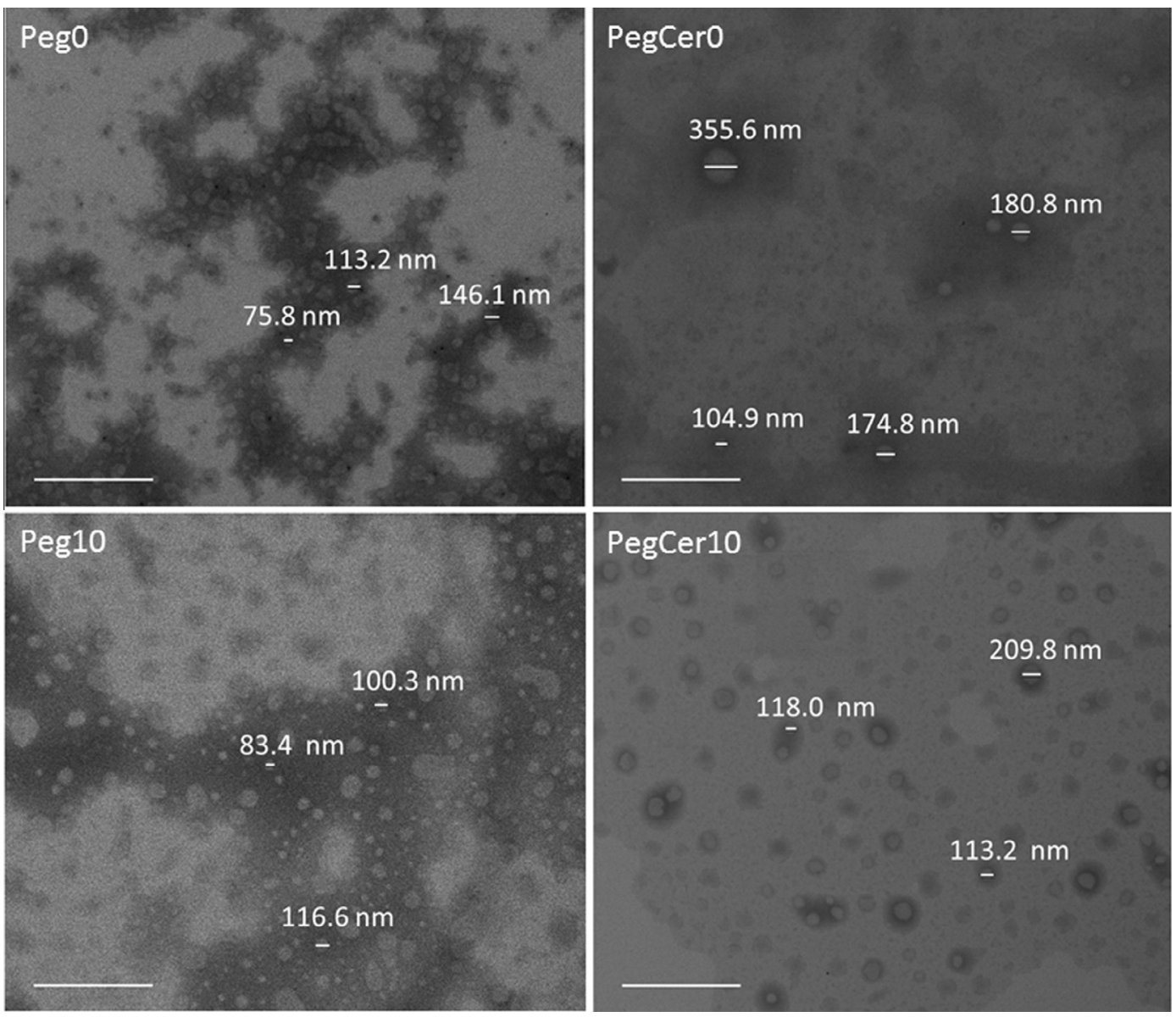

Fig. 3. STEM micrographs of Peg0, Peg10, PegCer0 and PegCer10 DODAB:MO (2:1) liposome dispersions. Scale bar $1.2 \mu \mathrm{m}$.

fluorescence intensity peak of HSA, along with a slight blue shift of the signal, were observed. An example of the interaction of the liposomes with HSA, at $25^{\circ} \mathrm{C}$, is presented in Supplementary information (Figs. S4 and S5). The binding constants $K_{\mathrm{b}}$ calculated from the fluorescence spectra are shown in Fig. 5A. It can be seen that, for the same temperature, the presence of PEG-Cer decreases the binding of HSA to liposomes (PegCer0 $>$ PegCer $5>$ PegCer15). For the pegylated liposomes, $K_{\mathrm{b}}$ slightly increases from 25 to $30^{\circ} \mathrm{C}$, and then it decreases again for $37^{\circ} \mathrm{C}$. For all situations, the calculated binding sites were between 0.915 and 1.130 , which indicates one possible binding site between HSA and liposomes. Fig. 5B shows that the Gibbs free energy $(\Delta G)$ calculated for the interaction between the protein and the liposomes is negative, meaning that the binding occurs spontaneously. As the temperature increases, $\Delta G$ becomes slightly more negative for the non-pegylated liposomes, while this trend is verified for pegylated formulations only at $37^{\circ} \mathrm{C}$. This suggests that the binding between liposomes and HSA becomes more spontaneous ( $\Delta G$ becomes more negative) with temperature increase.

In Fig. $5 \mathrm{C}$, it is possible to observe that, although liposomes interact with HSA (Figs. S4 and S5), none of the siRNA-lipoplexes tested induced significant changes on the tryptophan fluorescence emission spectra of HSA, fibrinogen and globulins, thus no conformational changes of the serum proteins were induced, at physiological $\mathrm{pH}$, by exposure to lipoplexes.

\subsection{PEG-Cer siRNA-lipoplexes induce good cellular responses}

The effect of each pegylation strategy was evaluated in terms of cellular internalization, cytotoxicity and EGFP silencing efficiency of siRNA-lipoplexes in vitro. Additionally, the siRNA-lipoplex bioactivity in a relevant leukemia cell model was assessed for therapeutic $B C R-A B L$ silencing.

EGFP gene silencing efficiency, cytotoxicity and cellular internalization on H1299 cells are depicted in Fig. 6.

The two pegylation strategies had a different impact on gene silencing efficiency of the siRNA-lipoplexes (Fig. 6A): the presence of 5\% (mol:mol) DSPE-PEG drastically decreased EGFP downregulation, while PEG-Cer did not significantly influence it.

The cytotoxicity of the nanocarriers was also evaluated, to exclude the possibility of a higher toxicity limiting the silencing effect. The siRNA-lipoplexes did not induce a significant cytotoxic response and no variation was observed across samples (Fig. 6B). The different pegylation strategies also had a dissimilar impact on siRNA-lipoplex cellular internalization, resulting in slightly higher total mean fluorescence intensity (MFI) for PegCer when compared to Peg lipoplexes (data not shown). Fig. 6C clearly shows that the presence of DSPE-PEG at the surface of siRNA-lipoplexes reduced the nanocarriers' cellular uptake. One should nevertheless mention that a high number of cells internalized some siRNA-lipoplexes, for pegylated and non-pegylated DSPE-PEG lipoplexes. When siRNA-lipoplexes were post-pegylated with PEG-Cer, approximately the same levels of fluorescence were detected for all siRNA-lipoplexes (Fig. 6C). The cellular internalization of siRNA-lipoplexes was additionally confirmed by CLSM (Fig. 7).

After the $4 \mathrm{~h}$-incubation period, siRNA-lipoplexes were clearly inside the cytoplasm of the cells, showing a higher internalization for PegCer when compared to Peg lipoplexes, and therefore corroborating the results obtained by flow cytometry. siRNA-lipoplexes seem to be localized close the nucleus, but a conclusion about 
siRNA release

siRNA-lipoplexes aggregation

A

$\square$ HEPES UI HS (1h)

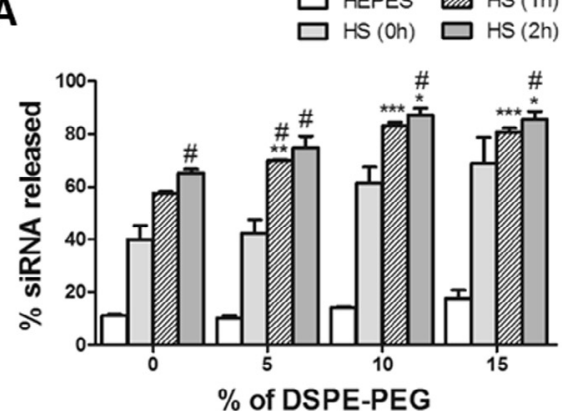

C

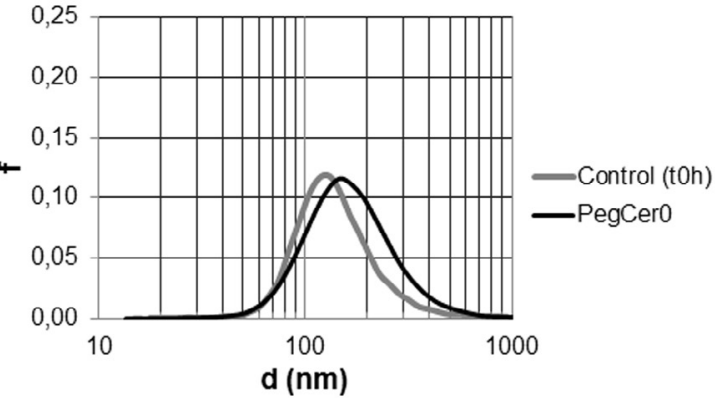

B
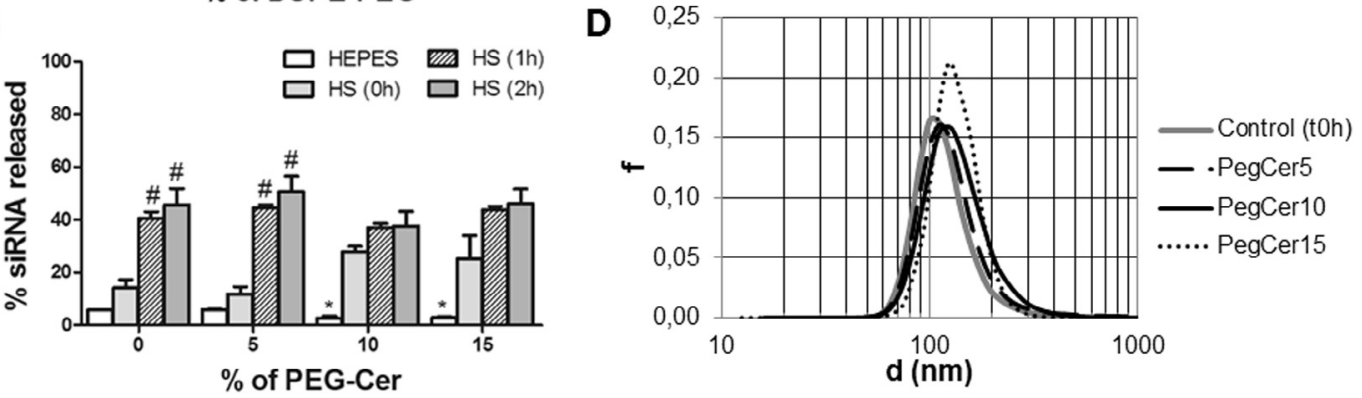

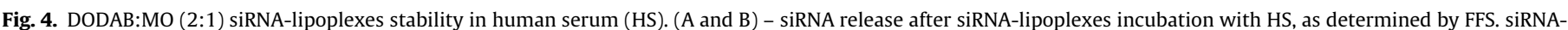

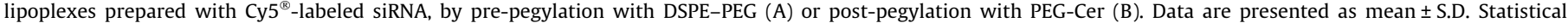

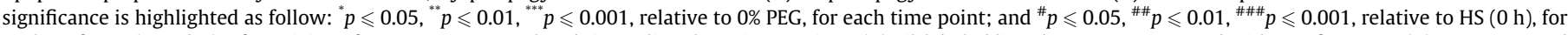

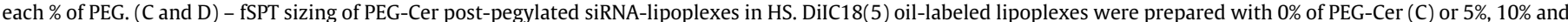

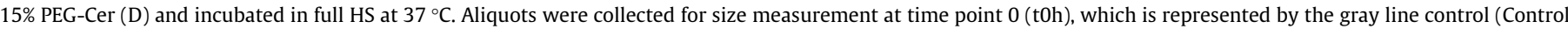

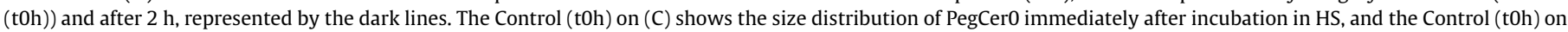
(D) is representative of PegCer5, 10 and 15 immediately after incubation in HS. All siRNA-lipoplexes were prepared at charge ratio (+/-) 15.

A
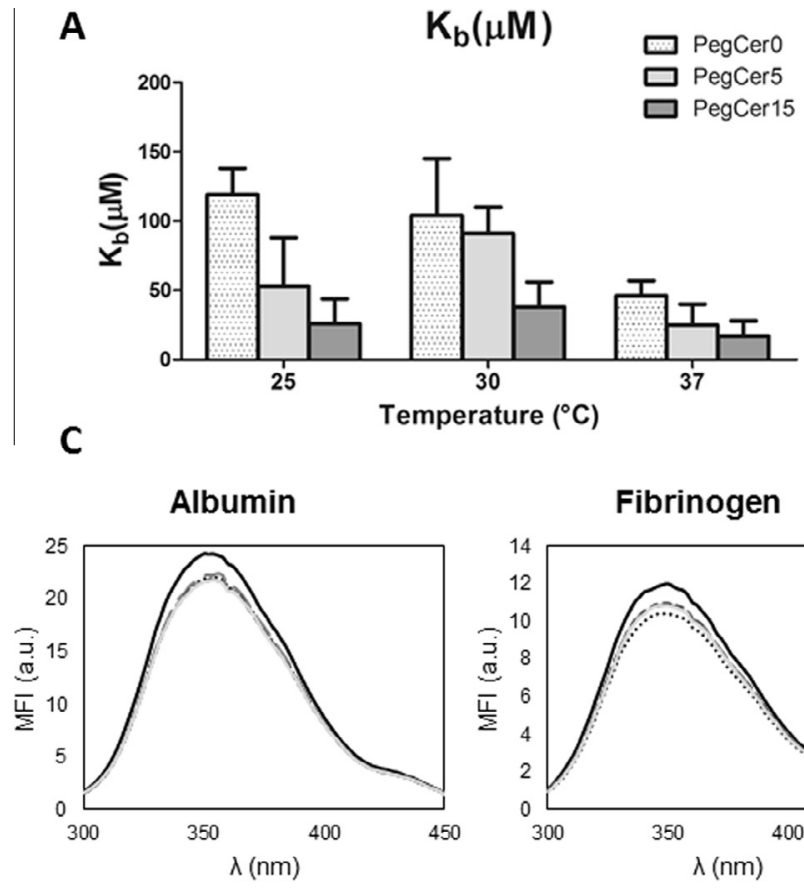

Albumin

C
Fibrinogen

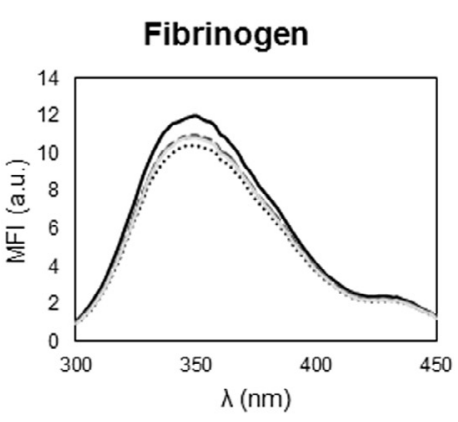

B

\begin{tabular}{|cccc|}
\hline \multicolumn{4}{|c|}{$\Delta \mathbf{G}_{\text {binding }}(\mathrm{Kcal} / \mathrm{mol})$} \\
\hline $\mathbf{T}\left({ }^{\circ} \mathbf{C}\right)$ & PegCer0 & PegCer5 & PegCer15 \\
\hline $\mathbf{2 5}$ & $-5,35$ & $-5,82$ & $-6,25$ \\
\hline $\mathbf{3 0}$ & $-5,64$ & $-5,44$ & $-6,26$ \\
\hline $\mathbf{3 7}$ & $-6,15$ & $-6,52$ & $-6,76$ \\
\hline
\end{tabular}

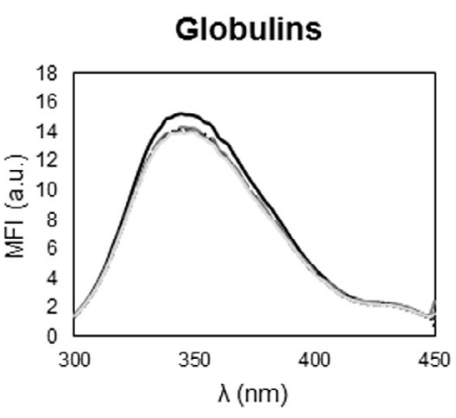

- Protein

......... PegCer0

- - PegCer5

-.-..PegCer10

PegCer15

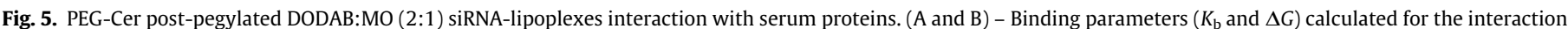

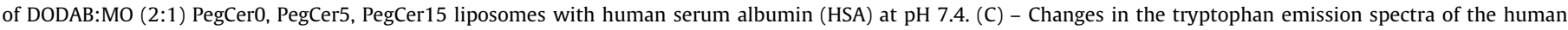
proteins albumin, fibrinogen, and globulins, when incubated with DODAB:MO (2:1) siRNA-lipoplexes in PBS, pH 7.4.

the nanocarriers' co-localization with endosomes or lysosomes cannot be made (Fig. $6 \mathrm{~A}^{\prime}-\mathrm{D}^{\prime}$ ).

DODAB:MO (2:1) siRNA-lipoplexes were finally evaluated on a relevant human myelogenous leukemia cell line. The silencing efficiency of DODAB:MO (2:1) siRNA-lipoplexes was determined by quantitative real time PCR (qPCR) in the K562 cell line, using $B C R-A B L$ as the gene target. Additionally, the effects of $B C R-A B L$ downregulation on K562 cell survival were determined by a 

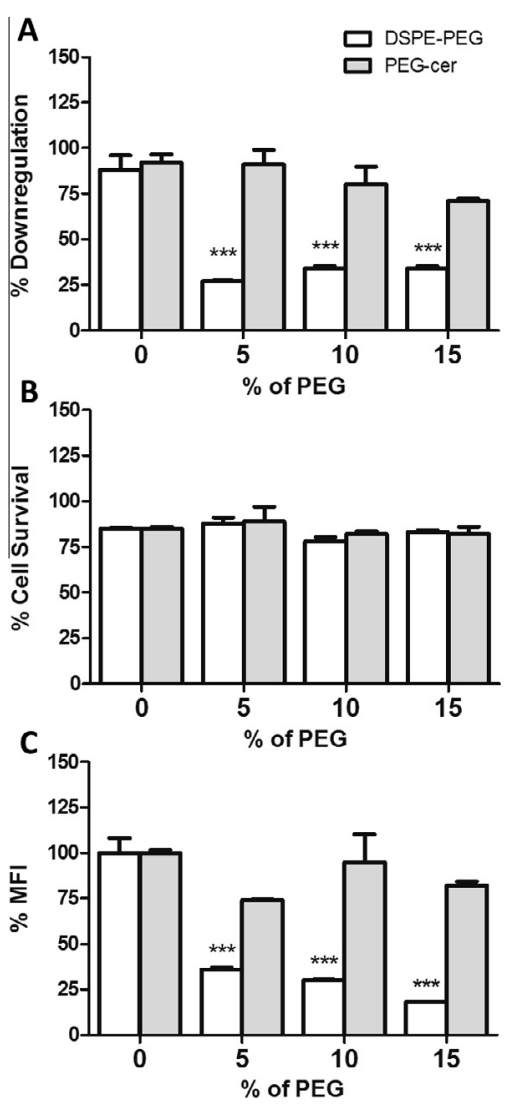

Fig. 6. In vitro evaluation of the pegylation strategy of DODAB:MO (2:1) siRNAlipoplexes. (A) - EGFP silencing efficiency of siRNA-lipoplexes. H1299 eGFP cells incubated with siRNA-lipoplexes for $4 \mathrm{~h}$ and transfection efficiency determined by flow cytometry after $48 \mathrm{~h}$. Control siRNA (siCTRL) and active siRNA (siEGFP) were used to prepare the lipoplexes, and the percentage of cells with significant knockdown was determined. (B) - Metabolic cytotoxicity induced by siRNA-lipoplexes. H1299 eGFP cells incubated with siRNA-lipoplexes for $4 \mathrm{~h}$ and MTT assay performed after $48 \mathrm{~h}$. Non-treated cells considered as $100 \%$ cell survival. (C) - Cellular uptake of siRNA-lipoplexes. H1299 eGFFP cells incubated at $37^{\circ} \mathrm{C}$ with Cy $5{ }^{\circledR}$-labeled siRNA-lipoplexes, and after $4 \mathrm{~h}$, uptake was determined by flow cytometry. The mean fluorescence intensity (MFI) of cells treated with Peg0 and PegCer0 was defined as $100 \%$, \% MFI of Peg5, 10 and 15 was calculated against Peg0, and \% MFI of PegCer5, 10 and 15 calculated against PegCer0. siRNA-lipoplexes were prepared at charge ratio $(+/-) 15$. Data are presented as mean \pm S.D. Statistical significance is highlighted as follow: ${ }^{*} p \leqslant 0.05,{ }^{* *} p \leqslant 0.01,{ }^{* * *} p \leqslant 0.001$, relative to $0 \%$ PEG, for each type of PEG.

cytotoxicity assay. Fig. 8 shows the relative $B C R-A B L$ gene expression and the percentage of $\mathrm{K} 562$ cell survival after treatment with siRNA-lipoplexes.

BCR-ABL knockdown efficiency was evaluated on the K562 cell line transfected with non-pegylated (PegCer0) and the most promising post-pegylated DODAB:MO (2:1) siRNA-lipoplex (PegCer10). This formulation has the required concentration of PEG to avoid siRNA release (Fig. 4B) and siRNA-lipoplexes aggregation (Fig. 4D) in human serum. Additionally, the PegCer10 siRNA-lipoplexes are well internalized and have high silencing efficiency on H1299eGFP cells (Fig. 6). The commercial system Lipofectamine RNAiMax ${ }^{\circledR}$ was used as a positive control, and Peg10 siRNA-lipoplexes were included for comparison. Fig. 8A shows that all nanocarriers decreased $B C R-A B L$ mRNA levels, with a higher efficiency for PegCer0 lipoplexes and Lipofectamine RNAiMax $^{\circledR}$. The same result was obtain at the BCR-ABL protein expression level (Supplementary information, Fig. S6). A decrease in cell survival was observed $72 \mathrm{~h}$ after treatment with PegCer0, PegCer10 and Lipofectamine RNAiMax ${ }^{\circledR}$ encapsulating siBCR-ABL, but not with liposomes encapsulating scrambled siRNA or empty liposomes (Fig. 8B). When the effective cell survival was determined to consider the cytotoxicity induced by the respective empty vectors, PegCer0 becomes the more effective nanocarrier.

\section{Discussion}

The objective of this work was to optimize DODAB:MO $(2: 1)$ liposomes for systemic siRNA delivery. Our approach to produce stealth DODAB:MO (2:1) siRNA-lipoplexes was to choose reported pegylation strategies that have proven to be successful in promoting cell transfection: (i) pre-pegylation with DSPE-PEG and (ii) post-pegylation with PEG-Cer [23,25]. While DSPE-PEG can be stably incorporated into the liposome bilayer and provide excellent stability to liposomes in serum [18], such a stable PEG coating might interfere with efficient uptake and endosomal escape in cells. PEG-Cer functionalization, on one hand, provides a less stable PEG coating with reduced colloidal stability [18] but, on the other, it has a better chance to maintain cell transfection capabilities.

The pegylation of DODAB:MO (2:1) liposomes/lipoplexes was successfully achieved with both tested strategies, as demonstrated by the decrease of the surface charge of the nanocarriers (Table 2). Additionally, both methods were suitable for the preparation of homogeneous dispersions of small siRNA-lipoplexes (Table 2, Fig. 3), independently of the PEG-lipid used, meeting the size requirements for the prevention of clogging of capillaries and allow nanocarrier extravasation throughout the fenestrae of capillaries (400-600 nm) [39-41]. Nevertheless, DSPE-PEG had a more pronounced effect on the $\zeta$-potential than PEG-Cer, as previously observed with other formulations [23], and the heating step required for the incorporation of PEG-Cer chains on the liposomal membranes influenced, per se, the surface charge of liposomes. This result was previously obtained for pDNA delivery systems, where increasing the temperature from 25 to $50^{\circ} \mathrm{C}$ promoted the re-organization of DODAB and MO molecules within the liposomal formulation, resulting in a positive charge re-localization and consequent $\zeta$-potential increase [42]. Additionally, it was previously observed by DSC that the transition temperature $\left(T_{\mathrm{m}}\right)$ determined in the cooling mode is $6{ }^{\circ} \mathrm{C}$ lower when compared to the $T_{\mathrm{m}}$ determined in the heating mode, with the same enthalpy [34], suggesting that the heating/cooling process may influence the liposomes morphology in an irreversible way. It was also shown before that increasing the temperature of DODAB:MO (2:1) liposomes had a similar effect on the nanocarriers morphology as the effect of increasing the monoolein content of the formulation [29,42]. These previous results $[29,34,42]$, together with the observed increase in the $\zeta$-potential of siRNA-lipoplexes (Table 2), as well as the difference on the percentage of siRNA released from Peg0 and PegCer0 lipoplexes (Fig. 4A and B), support the hypothesis that increasing the temperature promoted a structural re-organization of DODAB:MO (2:1) siRNA-lipoplexes. Moreover, the heating step used to prepare the PEG-Cer coating lead to a better protection of encapsulated siRNA.

It is well known that gene delivery systems must have specific characteristics in order to achieve the desired therapeutic effect. For example, nanocarriers must be able to efficiently encapsulate siRNA and protect it in biological interfaces; should not aggregate in physiological conditions to prevent clogging of capillaries, extravasate throughout the fenestrae of capillaries, as well as avoid immune recognition; must be well internalized by target cells; and must be able to release their siRNA content into the cytoplasm for incorporation in the RISC complex. We have performed a series of experiments in order to evaluate some of these characteristics, and found that post-pegylation of DODAB:MO (2:1) lead to a better performance of siRNA-lipoplexes. 

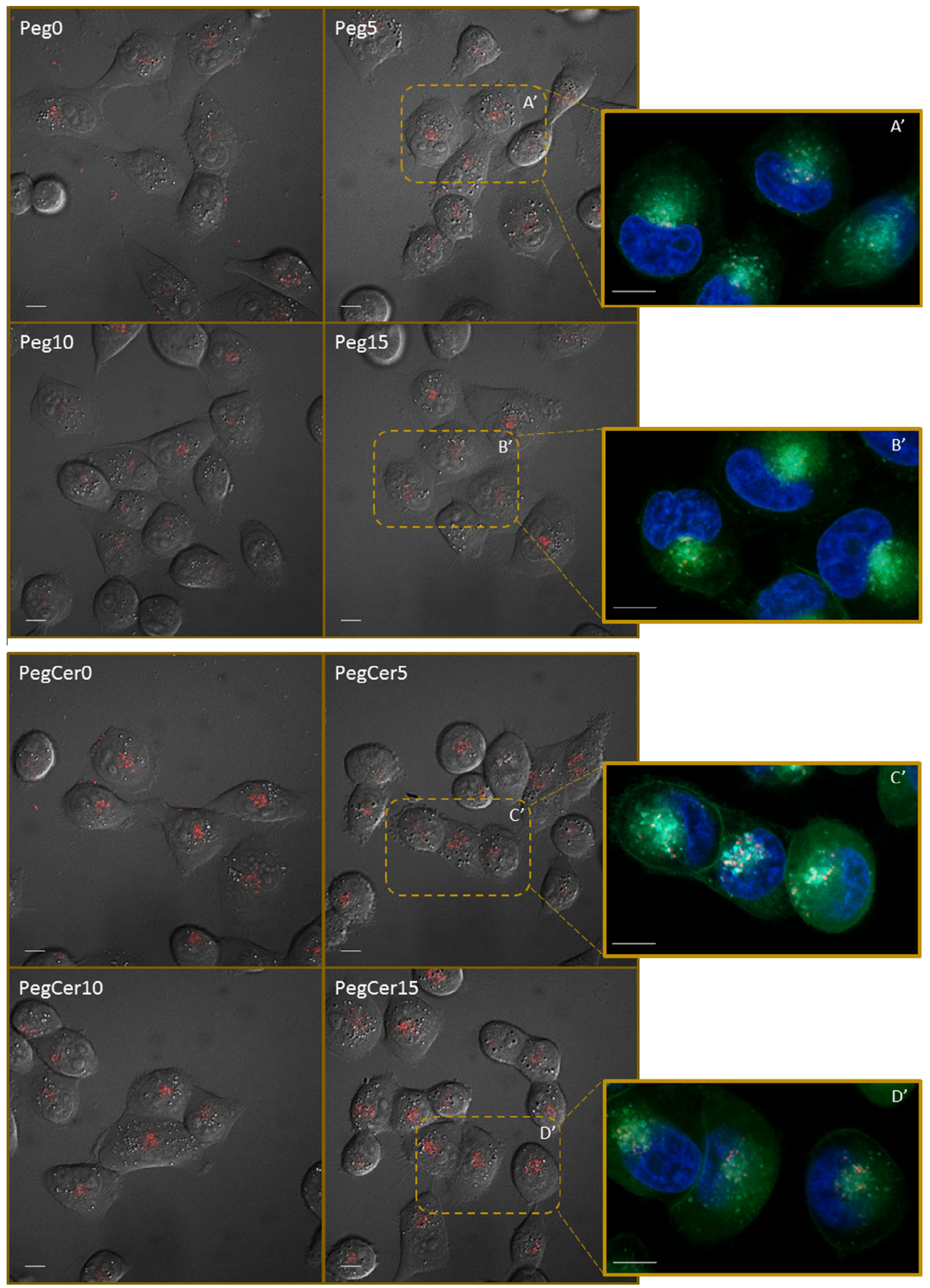

Fig. 7. Uptake of pegylated DODAB:MO (2:1) siRNA-lipoplexes. Intracellular distribution of siRNA-lipoplexes after 4 h incubation with H1299 wild type cells. Lipoplexes were prepared with Cy5 ${ }^{\circledR}$-labeled siRNA (red). A'-D' display magnifications of cells treated with Peg5 (A), Peg15 (B), PegCer5 (C) and PegCer15 (D) siRNA-lipoplexes, respectively, showing endo-lysosomal compartments labeled with LysoSensor Green ${ }^{\circledR}$ (green) and cell nucleus with Hoechst (blue). Scale bar $10 \mu \mathrm{m}$. (For interpretation of the references to color in this figure legend, the reader is referred to the web version of this article.)

Fig. 4A and B show that PegCer lipoplexes release less siRNA, not only in HEPES buffer, but also when incubated in human serum. The mechanism proposed for lipoplex formation suggests that nucleic acids bind to the surface of the cationic liposomes, inducing a close contact between nearby liposomes, that ultimately results in the fusion and entrapment of the genetic material between lipid bilayers $[43,44]$. In the case of pre-pegylated lipoplexes, although nucleic acids also bind to liposomal surfaces, close contact between liposomes is prevented by the PEG-chains, avoiding fusion and consequent entrapment [45]. As a result, nucleic acids likely remain at the surface of pegylated liposomes and are less protected. Our results show that pre-pegylation had a negative effect on siRNA complexation, as seen by the higher percentage of siRNA that is released upon dispersion in HS (cfr. 

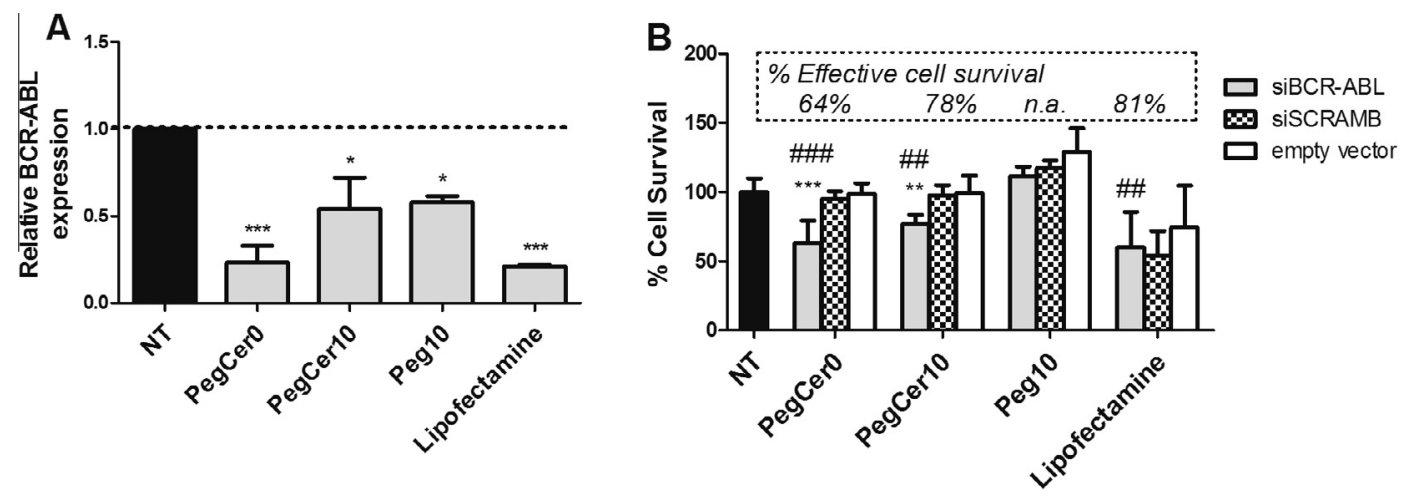

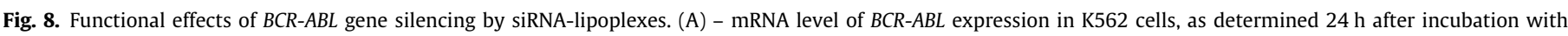

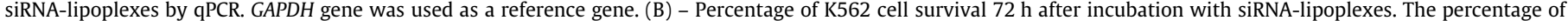

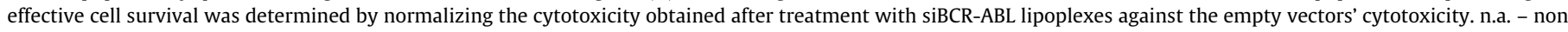

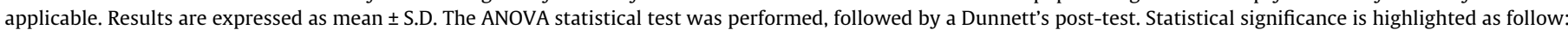

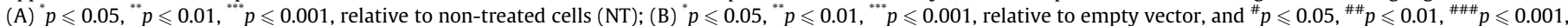
relative to non-treated cells (NT).

Fig. 4A and B). The percentages of siRNA encapsulation are in agreement with the values found in literature $[12,46]$. As Fig. 4 also demonstrates, pegylated lipoplexes were more susceptible to siRNA displacement than non-pegylated siRNA-lipoplexes, although other studies have found that incubation of both non-pegylated and pegylated siRNA-lipoplexes in full HS released over 90\% siRNA [16]. This displacement is essentially driven by the high protein concentrations present in serum, as competition between negatively charged proteins and siRNA molecules for the positive charges of liposomes is thought to occur [16]. If siRNA localizes inside of the lipid bilayers, it will be less susceptible to be displaced by proteins [45]. Studies with polymers have also shown a more firm compaction of nucleic acids by PEI (polyethylenimine) than PEG-PEI, providing a better protection of siRNA against enzymatic degradation [24]. Post-pegylation resulted in reduced siRNA displacement because PEG-chains did not interfere with the siRNA encapsulation, allowing its protection inside lipid bilayers.

Fig. 4C and D show that PegCer coating is stable enough to prevent aggregation in undiluted human serum for $2 \mathrm{~h}$. Our findings agree well with results obtained for other nanocarriers, which demonstrated aggregation of non-pegylated liposomes and nanogels when dispersed in serum [18,19]. But as observed for DODAB:MO (2:1) siRNA-lipoplexes (Fig. 4), aggregation of nanogels could be slowed down by modifying their surface with PEG [19]. Our results show that PEG-Cer coating of DODAB:MO $(2: 1)$ siRNA-lipoplexes was able to reduce aggregation in full HS, which probably is a consequence of a decreased of proteins to the nanocarriers. Therefore, PegCer liposomes present a better encapsulation efficiency and siRNA protection than DSPE-PEG liposomes, as well as a good colloidal stability in biological fluids. siRNA dissociation from lipoplexes before entering the cells will likely decrease pre-pegylated lipoplexes silencing efficiency.

Fig. 6C shows that PegCer lipoplexes are better internalized by H1299 cells. PEG-Cer reduced less the surface charge of siRNA-lipoplexes than DSPE-PEG (Table 2), which could account for enhanced interaction with negatively charged cell membranes and consequent higher internalization. A better internalization will definitely improve the possibility for gene silencing. Actually, in line with these findings, our results also showed that the coating with PEG-Cer was more efficient in promoting EGFP downregulation in H1299 eGPF cells than the coating with DSPE-PEG (Fig. 6A).

One of the main drawbacks of pegylation is the reduction on the efficiency with which lipoplexes can induce escape of siRNA molecules from the endosomes in which they are located after cell uptake [25,26]. For non-pegylated lipoplexes the presence of a helper lipid in the formulation helps on the release of the genetic material from endosomes [26,46-48], while the presence of PEG at the nanocarrier surface blocks this release by more than one mechanism. First, PEG favors a stable lamellar lipid organization, impairing the modification into another structural organization required for endosomal membrane destabilization [25,49]; second, PEG also prevents the close interaction between lipoplexes and endosomal membranes required for destabilization and nucleic acids release [50]. As stated earlier, stealth strategies with different PEG moieties will influence the strength of PEG anchorage to the liposome bilayer, and this will influence the de-pegylation process [51], which in turn controls lipoplexes' escape from endosomes and thus the silencing efficiency of the system. In the case of DSPE-PEG, PEG is anchored by DSPE, a zwitterionic phospholipid with double $\mathrm{C} 18$ acyl chains, while in PEG-ceramide the anchorage is made through ceramide C8 (Fig. 1). The smaller the acyl chains of the lipids anchored to PEG, the faster the diffusion kinetics [52]. Dialkyl phospholipid residues with C14-C18 hydrocarbon chains anchored to PEG usually transfer between membranes via monomer diffusion, with half-times of a few tens of hours or less [53]. Consequently, faster de-pegylation is expected to occur for PegCer siRNA-lipoplexes, probably due to ceramide's smaller acyl chains and double bond [52]. Furthermore, since too fast de-pegylation can compromise the colloidal stability of the system, the ability of PEG-Cer pegylation to efficiently avoid aggregation of siRNA-lipoplexes in human serum was studied.

The main purpose of pegylation is to decrease binding of proteins to the nanocarriers, which might induce release of the cargo, aggregation of the nanocarriers and activation of the immune system. As expected, at physiological temperature $\left(37^{\circ} \mathrm{C}\right)$ not only the presence of PEG-Cer decreased the binding of HSA when compared to the non-pegylated liposomes, but also the $K_{\mathrm{b}}$ was lower that the $K_{\mathrm{b}}$ determined for $25^{\circ} \mathrm{C}$. Therefore, the increase in temperature influenced the binding process. The increase in temperature towards the transition temperature of the liposomes $\left(T_{\mathrm{m}} 47.1^{\circ} \mathrm{C}\right.$ [34]) lead to the re-organization of DODAB and MO, and has the same effect as increasing the MO content of liposomes [42]. Therefore, it is expected that a higher mobility induced by MO can destabilize the liposomes structure, favoring the binding of proteins even in the presence of PEG. After a certain temperature (between 30 and $37^{\circ} \mathrm{C}$ ), the lipid rearrangements will allow MO to adopt a conformation that can stabilize the liposome structure, decreasing the binding of HSA, not only in the presence of PEG, but also for the non-pegylated liposomes. Actually, it was previously 
found that DODAB does not incorporate MO in a very homogeneous way, forming DODAB- and MO-rich domains [34]. Therefore, proteins can bind preferentially to one of these regions. As the temperature increases, the lipid bilayers become more homogeneous, and MO or DODAB-enriched domains are less frequent, decreasing the interaction with proteins. The fact that the association between proteins and liposomal membranes is dependent on the membrane structural properties and conditions of phase separation was already described, in addition to the effect of the composition of the lipid bilayers [54,55]. The calculated $K_{\mathrm{b}}$ values were generally $<100 \mu \mathrm{M}$, indicating strong binding between the liposomes and the protein.

Not only did we evaluate the binding of proteins to the liposomes, but also the protein conformational changes that siRNA-lipoplexes induce into human serum proteins, to assure that protein functions, such as the clottability of fibrinogen, will not be affected by these interactions. The alteration of the protein fluorescence signal can indicate that they are denaturated, as found by Simón-Vázquez et al. [37] for ZnO nanoparticles. Our results showed that none of the siRNA-lipoplexes induced significant changes on the tryptophan fluorescence emission spectra of HSA, fibrinogen and globulins (Fig. 5C). This is another indication of the biocompatibility of these nanocarriers, together with the fact that all DODAB:MO (2:1) siRNA-lipoplexes were found to be well tolerated by the cells (Fig. $6 \mathrm{~B}$ and Fig. 8B), in line with what was observed before in other cellular models for MO-based nanocarriers $[28,30,34]$.

The suitability of the pegylated nanocarriers towards a clinical application was finally evaluated by measuring the silencing efficiency on a relevant leukemia model cell line, as well as the effect of the gene downregulation on cell survival. The human myelogenous leukemia cell line K562 expresses the $B C R-A B L$ oncogene, that results from the $\mathrm{t}(9 ; 22)(\mathrm{q} 34 ; \mathrm{q} 11)$ reciprocal translocation between chromosomes 9 and 22, and causes chronic myeloid leukemia (CML). BCR-ABL encodes the BCR-ABL protein, a constitutively active tyrosine kinase, responsible for malignant transformation. Therefore, silencing $B C R-A B L$ is an approach that is being explored for CML treatment [56-58]. Our siRNA-lipoplexes were found to efficiently downregulate $B C R-A B L$ gene expression (Fig. $8 \mathrm{~A}$ ), reduce protein expression (Supplementary information, Fig. S6), and decrease K562 cell survival (Fig. 8B). Although both pegylation strategies produced siRNA-lipoplexes able to decrease BCR-ABL expression, this effect was not translated in a reduction of cell survival for Peg10 siRNA-lipoplexes. Non-pegylated nanocarriers achieved higher levels of $B C R-A B L$ gene silencing efficiency, but the silencing effects obtained with pegylated lipoplexes were still enough to affect K562 survival (Fig. 8B).

Our results show that post-pegylated DODAB:MO (2:1) liposomes encapsulate more siRNA, provide better protection in biological conditions, do not aggregate in serum, do not induce conformational changes to serum proteins, are better internalized by cells, and are apparently more efficient in allowing siRNA release from endosomes. We believe that the ability to decrease K562 cell survival, associated with a good stability in human serum, support PEG-Cer DODAB:MO (2:1) liposomes as promising siRNA delivery systems for cancer treatment.

Validation of these nanocarriers is currently being prepared in a murine model of cancer. As demonstrated in the current study, DODAB:MO (2:1) siRNA-lipoplexes have been designed to obtain the most favorable physicochemical characteristics for in vivo application. Specific gene silencing on a relevant in vitro model has also been successfully achieved. The proven protection in serum conferred by liposomes should allow a greater accumulation of therapeutic siRNA in target cells and consequently reduce disease burden. Furthermore, in a parallel study, repeated application of DODAB:MO liposomes was well tolerated by mice [59] in terms of toxicity and recognition by the immune system, and the desired biological effect was reached. Thus, it is expected that a good clinical response will be obtained for DODAB:MO (2:1) siRNA-lipoplexes directed against a relevant molecular target in an in vivo cancer model.

\section{Conclusions}

The success of intravenous siRNA based therapies still depends on the development of efficient delivery vehicles. In this work we evaluated two strategies for pegylation of DODAB:MO (2:1) liposomes for siRNA delivery. The siRNA-lipoplexes were evaluated in vitro, using highly advanced microscopy and spectroscopy techniques, to understand how nanocarriers perform in complex body fluids before moving to in vivo tests.

The two strategies tested differ on the methodology used to include PEG onto the nanocarriers (pre and post-pegylation), that strongly influenced the siRNA encapsulation efficiency and siRNA protection ability. The use of DSPE-PEG or PEG-Cer had an impact on the kinetics of PEG release from the liposomes, which influenced the nanocarriers' stability in serum, cellular uptake and silencing activity of the systems.

DODAB:MO (2:1) post-pegylated with PEG-Cer resulted in better siRNA protection from displacement by serum proteins, better cellular internalization, and superior silencing efficiency. Additionally, the PEG-Cer nanocarriers had the ability to reduce binding of HSA to liposomes, slowing down aggregation in human serum, and had the potential to silence the $B C R-A B L$ gene in a leukemia cell line model, affecting cellular survival. Taking in consideration all the results, surface modification with PEG-Cer post-pegylation is suggested as a promising strategy for the in vivo successful application of DODAB:MO (2:1) siRNA-lipoplexes. Other published results by our group in mouse models [59] also lead us to believe the system will be well tolerated in vivo. The clinical usefulness of these vectors will soon be validated in an in vivo murine cancer model.

\section{Disclosures}

The authors declare the following competing financial interest(s): The University of Minho, M.E.C.D.R.O., and A.C.G. have filed patent applications of Portuguese Patent PT104158 (2011), European Patent EP2335687 A2 (2011), and International Patent WO2010/020935 A2 (2010), respectively.

\section{Acknowledgements}

This work was supported by FEDER through POFC-COMPETE and by national funds from FCT I.P. through the strategic funding UID/BIA/04050/2013 (CBMA) and PEst-C/FIS/UI0607/2013 (CFUM) and PTDC/QUI/69795/2006. We thank the support of the Frame Work Program 7 of the European Commission: BIOCAPS (316265, FP7/REGPOT) and Xunta de Galicia, Spain (Agrupamento INBIOMED, Grupo con potencial crecimiento) and postdoctoral fellowship for R. Simón-Vásquez. Marlene Lucio holds a position of Researcher FCT with the reference IF/00498/2012, while Ana Oliveira holds scholarship SFRH/BD/68588/2010. K. Raemdonck is a postdoctoral fellow of the Research Foundation - Flanders (FWO-Vlaanderen). We acknowledge NanoDelivery-I\&D em Bionanotecnologia, Lda. for access to their equipment. We also acknowledge George R. Dakwar for providing the human serum for FFS and fSPT experiments. 


\section{Appendix A. Supplementary data}

Supplementary data associated with this article can be found, in the online version, at http://dx.doi.org/10.1016/j.actbio.2015.07. 032.

\section{References}

[1] A. Fire, S. Xu, M.K. Montgomery, S.A. Kostas, S.E. Driver, C.C. Mello, Potent and specific genetic interference by double-stranded RNA in Caenorhabditis elegans, Nature 391 (1998) 806-811.

[2] J.K.W. Lam, W. Liang, H.-K. Chan, Pulmonary delivery of therapeutic siRNA, Adv. Drug Deliv. Rev. 64 (2012) 1-15.

[3] D. Bedi et al., Delivery of siRNA into breast cancer cells via phage fusion protein-targeted liposomes, Nanomedicine-UK 7 (2011) 315-323.

[4] Y. Chen, G. Cheng, R.I. Mahato, RNAi for treating hepatitis B viral infection, Pharm. Res. 25 (2008) 72-86.

[5] T.S. Lau, Y. Li, M. Kameoka, T.B. Ng, D.C.C. Wan, Suppression of HIV replication using RNA interference against HIV-1 integrase, FEBS Lett. 581 (2007) 32533259.

[6] L. Li, J. Hou, X. Liu, Y. Guo, Y. Wu, L. Zhang, Z. Yang, Nucleolin-targeting liposomes guided by aptamer AS1411 for the delivery of siRNA for the treatment of malignant melanomas, Biomaterials 35 (2014) 3840-3850.

[7] N. Khatri, D. Baradia, I. Vhora, M. Rathi, A. Misra, CRGD grafted liposomes containing inorganic nano-precipitate complexed siRNA for intracellular delivery in cancer cells, J. Control. Release 182 (2014) 45-57.

[8] D. Grimm, Small silencing RNAs: State-of-the-art, Adv. Drug Deliv. Rev. 61 (2009) 672-703.

[9] K.A. Whitehead, R. Langer, D.G. Anderson, Knocking down barriers: advances in siRNA delivery, Nat. Rev. Drug Discovery 8 (2009) 129-138.

[10] M. Dominska, D.M. Dykxhoorn, Breaking down the barriers: siRNA delivery and endosome escape, J. Cell Sci. 123 (2010) 1183-1189.

[11] J. Wang, Z. Lu, M.J. Wientjes, J.L.S. Au, Delivery of siRNA therapeutics: barriers and carriers, AAPS J. 12 (2010) 492-503.

[12] P. Resnier, T. Montier, V. Mathieu, J. Benoit, C. Passirani, A review of the current status of siRNA nanomedicines in the treatment of cancer, Biomaterials 34 (2013) 6429-6443.

[13] Y.-C. Tseng, S. Mozumdar, L. Huang, Lipid-based systemic delivery of siRNA, Adv. Drug Deliv. Rev. 61 (2009) 721-731.

[14] K. Bruno, Using drug-excipient interactions for siRNA delivery, Adv. Drug Deliv. Rev. 63 (2011) 1210-1226.

[15] K. Buyens, M. Meyer, E. Wagner, J. Demeester, S.C. De Smedt, N.N. Sanders, Monitoring the disassembly of siRNA polyplexes in serum is crucial for predicting their biological efficacy, J. Control. Release 141 (2010) 38-41.

[16] K. Buyens et al., A fast and sensitive method for measuring the integrity of siRNA-carrier complexes in full human serum, J. Control. Release 126 (2008) $67-76$

[17] G. Caracciolo, L. Callipo, S.C. De Sanctis, C. Cavaliere, D. Pozzi, A. Laganà, Surface adsorption of protein corona controls the cell internalization mechanism of DC-Chol-DOPE/DNA lipoplexes in serum, Biochim. Biophys. Acta 1798 (2010) 536-543.

[18] K. Braeckmans et al., Sizing nanomatter in biological fluids by fluorescence single particle tracking, Nano Lett. 10 (2010) 4435-4442.

[19] B. Naeye et al., Hemocompatibility of siRNA loaded dextran nanogels, Biomaterials 32 (2011) 9120-9127.

[20] C. Allen et al., Controlling the physical behavior and biological performance of liposome formulations through use of surface grafted poly(ethylene glycol), Biosci. Rep. 22 (2002) 225-250.

[21] S. Li, L. Huang, Pharmacokinetics and biodistribution of nanoparticles, Mol. Pharm. 5 (2008) 496-504.

[22] B. Romberg, W.E. Hennink, G. Storm, Sheddable coatings for long-circulating nanoparticles, Pharm. Res. 25 (2008) 55-71.

[23] L. Peeters, N.N. Sanders, A. Jones, J. Demeester, S.C. De Smedt, Post-pegylated lipoplexes are promising vehicles for gene delivery in RPE cells, J. Control. Release 121 (2007) 208-217.

[24] K. Remaut, B. Lucas, K. Raemdonck, K. Braeckmans, J. Demeester, S.C. De Smedt, Protection of oligonucleotides against enzymatic degradation by pegylated and nonpegylated branched polyethyleneimine, Biomacromolecules 8 (2007) $1333-1340$.

[25] F. Shi, L. Wasungu, A. Nomden, M.C.A. Stuart, E. Polushkin, J.B.F.N. Engberts, E. Hoekstra, Interference of poly(ethylene glycol)-lipid analogues with cationiclipid-mediated delivery of oligonucleotides; role of lipid exchangeability and non-lamellar transitions, Biochem. J. 366 (2002) 333-341.

[26] L.Y. Song, Q.F. Ahkong, Q. Rong, Z. Wang, S. Ansell, M.J. Hope, B. Mui, Characterization of the inhibitory effect of PEG-lipid conjugates on the intracellular delivery of plasmid and antisense DNA mediated by cationic lipid liposomes, Biochim. Biophys. Acta 1558 (2002) 1-13.

[27] J. Rejman, A. Wagenaar, J.B.F. Engberts, D. Hoekstra, Characterization and transfection properties of lipoplexes stabilized with novel exchangeable polyethylene glycol-lipid conjugates, Biochim. Biophys. Acta 1660 (2004) 41-52.
[28] J.P.N. Silva, A.C.N. Oliveira, M.P.P.A. Casal, A.C. Gomes, P.J.G. Coutinho, O.P. Coutinho, M.E.C.D. Real Oliveira, DODAB:monoolein-based lipoplexes as nonviral vectors for transfection of mammalian cells, Biochim. Biophys. Acta 1808 (2011) 2440-2449.

[29] I.M.S.C. Oliveira, J.P.N. Silva, E. Feitosa, E.F. Marques, E.M.S. Castanheira M.E.C.D. Real Oliveira, Aggregation behavior of aqueous dioctadecyldimethylammonium bromide/monoolein mixtures: a multitechnique investigation on the influence of composition and temperature, J. Colloid Interface Sci. 374 (2012) 206-217.

[30] J.P.N. Silva, A.C.N. Oliveira, A.C. Gomes, M.E.C.D. Real Oliveira, Development of dioctadecyldimethylammonium bromide/monoolein liposomes for gene delivery, in: Cell Interaction, InTech, Rijeka, 2012, pp. 245-272.

[31] J.P.N. Silva, I.M.S.C. Oliveira, A.C.N. Oliveira, M. Lúcio, A.C. Gomes, P.J.G. Coutinho, M.E.C.D. Real Oliveira, Structural dynamics and physicochemical properties of pDNA/DODAB:MO lipoplexes: effect of $\mathrm{pH}$ and anionic lipids in inverted non-lamellar phases versus lamellar phases, Biochim. Biophys. Acta 1838 (2014) 2555-2567.

[32] C. Leal, N.F. Bouxsein, K.K. Ewert, C.R. Safinya, Highly efficient gene silencing activity of siRNA embedded in a nanostructured gyroid cubic lipid matrix, J. Am. Chem. Soc. 132 (2010) 16841-16847.

[33] V. Luzzati, Biological significance of lipid polymorphism: the cubic phases, Curr. Opin. Struct. Biol. 224 (1997) 661-668.

[34] A.C.N. Oliveira et al., Dioctadecyldimethylammonium:Monoolein nanocarriers for efficient in vitro gene silencing, ACS Appl. Mater. Interfaces 6 (2014) 69776989.

[35] B. Naeye, K. Raemdonck, K. Remaut, B. Sproat, J. Demeester, S.C. De Smedt PEGylation of biodegradable dextran nanogels for siRNA delivery, Eur. J. Pharm. Sci. 40 (2010) 342-351.

[36] R.A. Copeland, Protein-ligand binding equilibria, in: Enzymes, Wiley-VCH, New York, 2000, pp. 76-95.

[37] R. Simón-Vázquez, T. Lozano-Fernández, M. Peleteiro-Olmedo, Á. GonzálezFernández, Conformational changes in human plasma proteins induced by metal oxide nanoparticles, Colloids Surf. B 113 (2014) 198-206.

[38] M.W. Pfaffl, A new mathematical model for relative quantification in real-time RT-PCR, Nucleic Acids Res. 29 (2001) 2002-2007.

[39] F. Braet, E. Wisse, Structural and functional aspects of liver sinusoidal endothelial cell fenestrae: a review, Comp. Hepatol. 1 (2002) 1-17.

[40] F. Yuan, M. Dellian, D. Fukumura, M. Leunig, D.A. Berk, V.P. Torchilin, R.K. Jain, Vascular permeability in a human tumor xenograft: molecular size dependence and cutoff size, Cancer Res. 55 (1995) 3752-3756.

[41] F. Yuan, Transvascular drug delivery in solid tumors, Semin. Radiat. Oncol. 8 (1998) 164-175.

[42] J.P.N. Silva, A.C.N. Oliveira, M. Lúcio, A.C. Gomes, P.J.G. Coutinho, M.E.C.D. Real Oliveira, Tunable pDNA/DODAB:MO lipoplexes: the effect of incubation temperature on pDNA/DODAB:MO lipoplexes structure and transfection efficiency, Colloids Surf. B 121 (2014) 371-379.

[43] V. Oberle, U. Bakowsky, I.S. Zuhorn, D. Hoekstra, Lipoplex formation under equilibrium conditions reveals a three-step mechanism, Biophys. J. 79 (2000) $1447-1454$.

[44] S. Weisman, D. Hirsch-Lerner, Y. Barenholz, Y. Talmon, Nanostructure of cationic lipid-oligonucleotide complexes, Biophys. J. 87 (2004) 609-614.

[45] K. Remaut, B. Lucas, K. Braeckmans, N.N. Sanders, J. Demeester, J.C. De Smedt, Protection of oligonucleotides against nucleases by pegylated and nonpegylated liposomes as studied by fluorescence correlation spectroscopy, J. Control. Release 110 (2005) 212-226.

[46] A.K. Kundu, P.K. Chandra, S. Hazari, Y.V. Pramar, S. Dash, T.K. Mandal, Development and optimization of nanosomal formulations for siRNA delivery to the liver, Eur. J. Pharm. Biopharm. 80 (2012) 257-267.

[47] I.S. Zuhorn, U. Bakowsky, E. Polushkin, W.H. Visser, M.C.A. Stuart, J.B.F.N. Engberts, D. Hoekstra, Nonbilayer phase of lipoplex-membrane mixture determines endosomal escape of genetic cargo and transfection efficiency, Mol. Ther. 11 (2005) 801-810.

[48] R. Koynova, L. Wang, R.C. Macdonald, An intracellular lamellar - nonlamellar phase transition rationalizes the superior performance of some cationic lipid transfection agents, Proc. Natl. Acad. Sci. U. S. A. 103 (2006) 14373-14378.

[49] Z. Hyvönen, S. Rönkkö, M.-R. Toppinen, I. Jääskeläinen, A. Plotniece, A. Urtti, Dioleoyl phosphatidylethanolamine and PEG-lipid conjugates modify DNA delivery mediated by 1,4-dihydropyridine amphiphiles, J. Control. Release 99 (2004) 177-190.

[50] I.M. Hafez, N. Maurer, P.R. Cullis, On the mechanism whereby cationic lipids promote intracellular delivery of polynucleic acids, Gene Ther. 8 (2001) 11881196.

[51] J.R. Silvius, R. Leventis, Spontaneous interbilayer transfer of phospholipids: dependence on acyl chain composition, Biochemistry 32 (1993) 13318-13326.

[52] J.J. Wheeler et al., Stabilized plasmid-lipid particles: construction and characterization, Gene Ther. 6 (1999) 271-281.

[53] J.R. Silvius, M.J. Zuckermann, Interbilayer transfer of phospholipid-anchored macromolecules via monomer diffusion, Biochemistry 32 (1993) 3153-3161.

[54] D. Lassiseraye, L. Courtemanche, A. Bergeron, P. Manjunath, M. Lafleur, Binding of bovine seminal plasma protein BSP-A1/-A2 to model membranes: lipid specificity and effect of the temperature, Biochim. Biophys. Acta 1778 (2008) 502-513.

[55] V. Anbazhagan, R.S. Sankhala, B.P. Singh, M.J. Swamy, Isothermal titration calorimetric studies on the interaction of the major bovine seminal plasma protein, PDC-109 with phospholipid membranes, PLoS One 6 (2001) e25993. 
[56] L.S. Mendonça, J.N. Moreira, M.C. Pedroso de Lima, S. Simões, Co-encapsulation of anti-BCR-ABL siRNA and imatinib mesylate in transferrin receptor-targeted sterically stabilized liposomes for chronic myeloid leukemia treatment, Biotechnol. Bioeng. 107 (2010) 884-893.

[57] L.S. Mendonça, F. Firmino, J.N. Moreira, M.C. Pedroso de Lima, S. Simões, Transferrin receptor-targeted liposomes encapsulating anti-BCR-ABL siRNA or asODN for chronic myeloid leukemia treatment, Bioconjugate Chem. 21 (2010) $157-168$
[58] L. Vellón, M. González-Cid, A. Karara, M.D.C. Nebel, M.T. Cuello, I. Larripa, Enhanced uptake of antisense oligonucleotides using cationic liposomes and the apoptotic effect of idarubicin in K-562 cell line, Leuk. Res. 26 (2002) 669676.

[59] C. Carneiro et al., DODAB:monoolein liposomes containing Candida albicans cell wall surface proteins: a novel adjuvant and delivery system, Eur. J. Pharm. Biopharm. 89 (2015) 190-200. 